\title{
An Alternative to Conventional Rock Fragmentation Methods Using SCDA: A Review
}

\author{
Radhika Vidanage De Silva ${ }^{1}$, Ranjith Pathegama Gamage ${ }^{1, *}$ and \\ Mandadige Samintha Anne Perera ${ }^{1,2}$ \\ 1 Deep Earth Energy Laboratory, Department of Civil Engineering, Monash University, Building 60, \\ Melbourne 3800, Victoria, Australia; radhika.desilva@monash.edu (R.V.D.S.); \\ samintha.perera@unimelb.edu.au (M.S.A.P.) \\ 2 Department of Infrastructure Engineering, Faculty of Engineering, the University of Melbourne, \\ Building 176, Block D, Grattan Street, Parkville 3010, Victoria, Australia \\ * Correspondence: ranjith.pg@monash.edu; Tel.: +61-3-9905-4982
}

Academic Editor: Moran Wang

Received: 9 October 2016; Accepted: 10 November 2016; Published: 17 November 2016

\begin{abstract}
Global energy and material consumption are expected to rise in exponential proportions during the next few decades, generating huge demands for deep earth energy (oil/gas) recovery and mineral processing. Under such circumstances, the continuation of existing methods in rock fragmentation in such applications is questionable due to the proven adverse environmental impacts associated with them. In this regard; the possibility of using more environmentally friendly options as Soundless Chemical Demolition Agents (SCDAs) play a vital role in replacing harmful conventional rock fragmentation techniques for gas; oil and mineral recovery. This study reviews up to date research on soundless cracking demolition agent (SCDA) application on rock fracturing including its limitations and strengths, possible applications in the petroleum industry and the possibility of using existing rock fragmentation models for SCDA-based rock fragmentation; also known as fracking. Though the expansive properties of SCDAs are currently used in some demolition works, the poor usage guidelines available reflect the insufficient research carried out on its material's behavior. SCDA is a cementitious powdery substance with quicklime $(\mathrm{CaO})$ as its primary ingredient that expands upon contact with water; which results in a huge expansive pressure if this $\mathrm{CaO}$ hydration reaction occurs in a confined condition. So, the mechanism can be used for rock fragmentation by injecting the SCDA into boreholes of a rock mass; where the resulting expansive pressure is sufficient to create an effective fracture network in the confined rock mass around the borehole. This expansive pressure development, however, dependent on many factors, where formation water content creates a negative influence on this due to required greater degree of hydration under greater water contents and temperature creates a positive influence by accelerating the reaction. Having a precise understanding of the fracture propagation mechanisms when using SCDA is important due to the formation of complex fracture networks in rocks. Several models can be found in the literature based on the tangential and radial stresses acting on a rock mass surrounding an SCDA charged borehole. Those fracture models with quasi-static fracturing mechanism that occurs in Mode I type tensile failure show compatibility with SCDA fracturing mechanisms. The effect of borehole diameter, spacing and the arrangement on expansive pressure generation and corresponding fracture network generation is important in the SCDA fracturing process and effective handling of them would pave the way to creating an optimum fracture network in a targeted rock formation. SCDA has many potential applications in unconventional gas and oil recovery and in-situ mining in mineral processing. However, effective utilization of SCDA in such application needs much extensive research on the performance of SCDA with respect to its potential applications, particularly when considering unique issues arising in using SCDA in different applications.
\end{abstract}


Keywords: soundless cracking demolition agents (SCDAs); expansive properties; volume expansion mechanism; rock fracturing; fracture mechanisms

\section{Introduction}

Rock fragmentation is associated with many applications in the field of energy and mineral recovery. Among the many methods used for fracturing of rock, the use of explosives and hydraulic fracturing are most widely employed in the field. Deep earth energy and resource recovery processes generally have bad public perceptions due to the numerous environmentally harmful activities associated with them. The increasing global energy and resource consumption from 1336 to $1894 \mathrm{~kg}$ of oil equivalent per capita in 2013 (30\% growth) within a span of four decades [1] has however led continuation of deep mining operations using conventional mining methods, despite the adverse environmental concerns. According to the projections of [2], the world energy consumption will grow by another $56 \%$ by 2040 and the possibility of continuing with harmful conventional fragmentation methods is a critical question that is required to bead dressed. This paper has been aimed at shedding light over the possibility of using soundless cracking demolition agents (SCDAs) as a more environmentally friendly replacement of conventional methods of rock fracturing.

\subsection{Explosive Blasting}

Rock blasting is the most primitive method used in rock fragmentation and is considered as the most economically viable rock fragmentation option compared to other fracturing mechanisms. However, use of explosives incorporates a lot of issues that need to be properly addressed for the desired result. In the case of deep mining, the difficulties in charging, sealing and controlling misfire are critical $[3,4]$ as those come up with various environmental issues as, ground excitations, generation of dust, air blast, fly rock and back-break [5-9].

The failure to effectively control the fragmentation through blasting is well reported and is the primary cause for back-break of rocks, which creates additional complications to the process, such as instability of underground mining walls, gas outbursts, a higher unpredictability of mine slope stability and ultimately leading to a heightened cost of mining operations [9-11]. Further, such uncontrolled explosions may create a large variation in the fragmented rock size while producing many fine particles. All of these well imply the issue of poor fragmentation and therefore needs to be controlled when using explosives to fracture rock [12]. This becomes further critical when considering the fact that fragments produced by rock blasting govern the efficiency of subsequent operations in the mineral liberation process [13].

\subsection{Hydraulic Fracturing}

On the other hand, the depletion of recoverable resources for energy production has led to the use of hydraulic fracturing to recover gas and oil from deep reservoirs. However, this technique has now been subjected to huge public opposition due to its application in highly populated and environmentally sensitive areas [14,15].

The main issue associated with hydraulic fracturing is the consumption of large volumes of fresh water for the fracturing operations, causing severe ecological impacts [14]. For example, the water requirement for fracturing of a shale play could be as large as 11-19 million liters of water for a single well [16], whereas more recent studies suggest that the water usage has increased up to 13.7-23.8 million liters per well [17]. Unless the injected water is treated and re-introduced into the hydrological system, nearly all the water used in hydraulic fracturing is lost. Further, trickling down of water used for fracturing through the target reservoir imposes the risk of contaminating subsurface aquifers and surface water withdrawals for hydraulic fracturing may change the quality and quantity of water in both surface and subsurface water bodies leading to ecological imbalances [18]. Induced 
seismicity from hydraulic fracturing is another controversial issue, of which the mechanisms are poorly understood [19]. Nevertheless, recent studies claim that injection-induced seismicity is real and has to be given due consideration as an adverse ecological impact [20,21].

Apart from those, the possible adverse effect on human health caused through toxic chemicals used in hydraulic fracturing is another dire aspect that has to be considered [22-25]. For example, the inclusion of carcinogens, such as formaldehyde, 2-butoxyethanol, and acetaldehyde to improve the fracturing performance of hydrofracturing increase the risk of contamination in surrounding drinking water sources [26]. Although water replacement fracturing techniques as foam-based fracturing can be used to minimize the issues in water-based fracturing $[25,27,28]$, those do not completely mitigate the issues related to the possible ground and surface water resources contaminations.

\subsection{Electrical Disintegration}

The electrical disintegration of rock is another fragmentation mechanism used in the mining industry, in which mineral liberation by sending high voltage electrical pulses into the formation. Though this has been identified as one of the fragmentation mechanisms with minimal environmental impacts [29-33], to date, this technology has however not been largely accepted by the mining and energy industry due to the huge transition that needs to be made from well-established mechanical disintegration processes [30]. Basically, the electrical disintegration of rock has limited application, mainly in the mineral liberation process, in which the generating current can be controlled. Application of this process in deep earth mines has however been inhibited due to the issues of controlling the generating current flow (2-6 kA) [31] in the presence of ground water. Furthermore, if applied in underground mines, the possible generation of excessive heat is another element which needs to be overcome by additional ventilation.

\section{Is There a More Effective Method for Rock Fragmentation?}

The adversities accompanying the use of conventional rock fragmentation processes along with the growing need to continue mining to sustain ever increasing population, the need to produce more effective alternate fragmentation mechanisms is clear.

SCDA also known as soundless cracking agents, expansive demolition agents, expansive concrete, non-explosive demolition agents [34-40], are such alternative rock fragmentation agents. The material used in the soundless cracking is a cementitious powdery substance and when it is hydrated at an appropriate temperature its quantity expands through the formation of ettringite $\left(3 \mathrm{CaO} \cdot \mathrm{Al}_{2} \mathrm{O}_{3} \cdot 3 \mathrm{CaSO}_{4} \cdot 32 \mathrm{H}_{2} \mathrm{O}\right)$ and calcium oxide $(\mathrm{CaO})$ hydration. In this process, the material is poured into the pre-drilled holes in the rock and the subsequent chemical reaction increases the temperature of the compound up to $150^{\circ} \mathrm{C}$ [41]. This allows the material to volumetrically expand over a period of several hours. Under the existing confinement in a borehole, this volumetric expansion generates an expansive pressure and when it exceeds the tensile strength of the rock cracks form [39]. Thus, SCDAs can eliminate almost all the drawbacks associated with explosive demolition.

Though expansive cement and SCDAs were initially introduced in the 1970s, they failed to penetrate the market due to the lack of established guidelines [42]. Despite its introduction over four decades ago, to date, not much information on physical and chemical characteristic of SCDA is known. Only a limited research has been conducted to date regarding the performance of SCDA compared to commercially available products.

\subsection{Commercially Available SCDA}

Despite subtle variations, the general usage guidelines available for each product shows the lack of research conducted on SCDAs. Table 1 shows specifications of commercially available SCDAs, in which only three aspects of each product is specified; water content, ambient temperature, and borehole diameter. Technical data relevant to the performance of SCDA is limited to the manufacturer specifications, those may highly deviate from the actual conditions. According to the conducted 
experiments on concrete fracturing, Laefer et al. [39], the time required for the first crack varied from 8 to $21 \mathrm{~h}$ at 38 and $24^{\circ} \mathrm{C}$, temperatures respectively, whereas the product specification indicates cracking occurs after 10 12 h of injection (Bristar, Table 1). This implies that the product specifications which are given on borehole diameter show extreme variation with experimental data. Boreholes with diameter $6.35 \mathrm{~mm}$ were successfully used by Gambatese [36] to generate controlled cracks in concrete, despite that requirement of minimal $32 \mathrm{~mm}$ diameter given in the product specification (Betonamit, Table 1).

Table 1. Types of commercially available SCDAs.

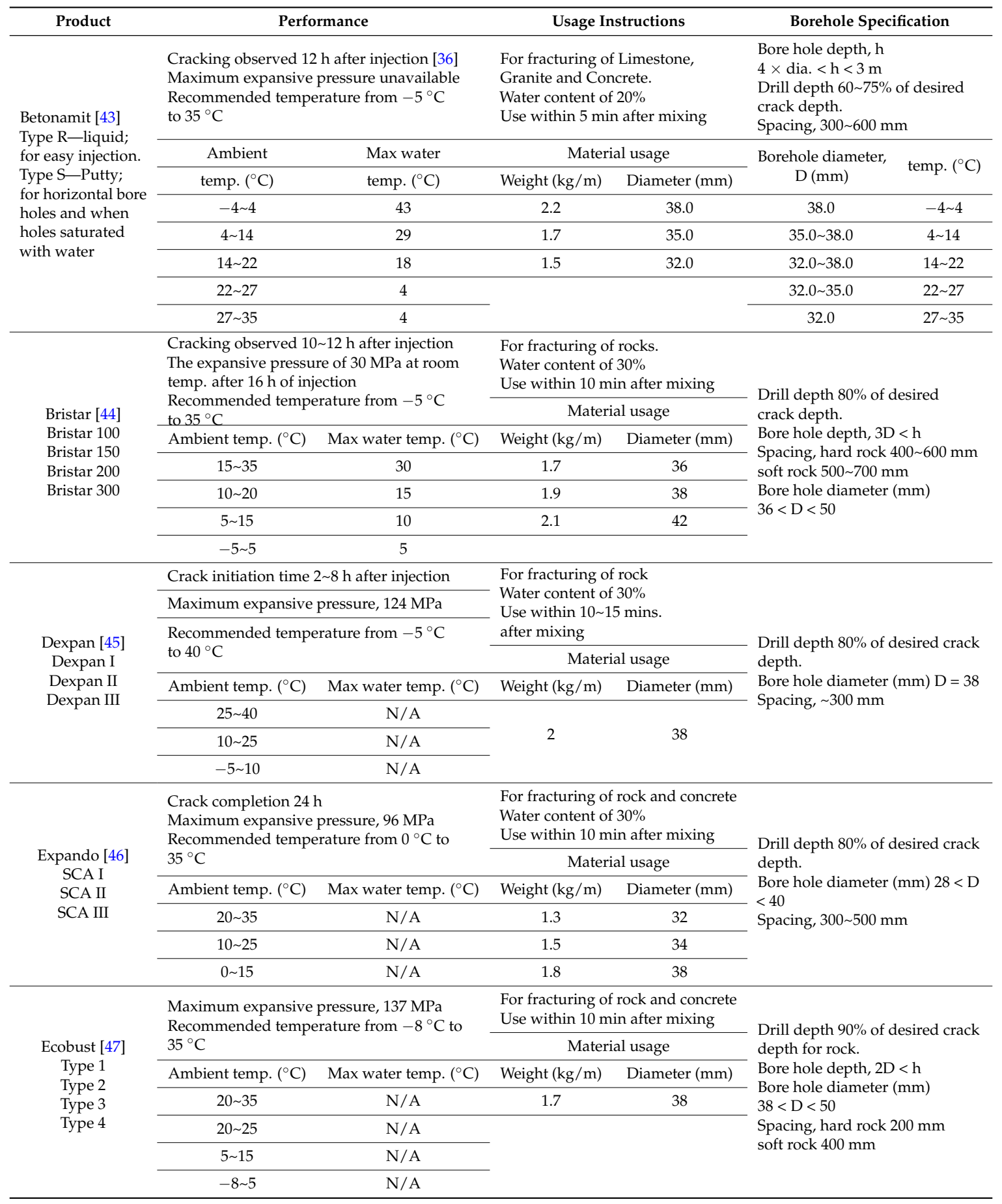




\subsection{Chemical Composition of SCDA}

Anhydrite $\left(\mathrm{CaSO}_{4}\right)$ and calcium oxide $(\mathrm{CaO})$ are the main expansive additives available in SCDA and have been combined with cement [48,49]. ASTM C 845-96 [50] classifies three categories of expansive cement based on its additives as follows.

1. Type $\mathrm{K}$ : Anhydrous calcium sulfoaluminate $\left(4 \mathrm{CaO} \cdot 3 \mathrm{Al}_{2} \mathrm{O}_{3} \cdot \mathrm{SO}_{3}\right)$, calcium sulfate $\left(\mathrm{CaSO}_{4}\right)$, and calcium oxide $(\mathrm{CaO})$;

2. Type M: Calcium aluminate $\left(\mathrm{CaO} \cdot \mathrm{Al}_{2} \mathrm{O}_{3}\right)$ and $\mathrm{CaSO}_{4}$;

3. Type S: Tricalcium aluminate $\left(\mathrm{CaO} \cdot \mathrm{Al}_{2} \mathrm{O}_{3}\right)$ and $\mathrm{CaSO}_{4}$.

Though there are many variations in the composition of SCDA reported in the literature [37,39-42,51], a more common chemical composition (as shown in Table 2) can be found in any type of SCDA with the major proportion of $\mathrm{CaO}$. A low content of $\mathrm{MgO}$ is also used to facilitate the formation of clinker in the production process of the material [52] and a low Sulphuric anhydrite $\left(\mathrm{SO}_{3}\right)$ content is used to regulate the quick and irregular setting of the slurry [53].

Table 2. Chemical composition of SCDA [37,39,42].

\begin{tabular}{cc}
\hline Chemical Components & Percentage by Mass (\%) \\
\hline $\mathrm{SiO}_{2}$ & $1.5-8.5$ \\
$\mathrm{Al}_{2} \mathrm{O}_{3}$ & $0.3-5.0$ \\
$\mathrm{Fe}_{2} \mathrm{O}_{3}$ & $0.2-3.0$ \\
$\mathrm{CaO}$ & $81-96$ \\
$\mathrm{MgO}$ & $0-1.6$ \\
$\mathrm{SO}_{3}$ & $0.6-4.0$ \\
\hline
\end{tabular}

The existing large proportion of $\mathrm{CaO}$ in the expansive cement means that the formation of hydrates could be similar to that of $\mathrm{K}$ type expansive cement. Figure 1 illustrates the expansive compounds generated in the presence of varying ratios of $\mathrm{CaO}, \mathrm{Al}_{2} \mathrm{O}_{3}$ and $\mathrm{SO}_{3}$. According to that, ettringite is generated at point $\mathrm{T}$ and $\mathrm{Ca}(\mathrm{OH})_{2}$ is generated on $\mathrm{CaO}$. High concentration of $\mathrm{CaO}$ in the liquid phase of the expansive cement during the hydration process, however, influences the magnitude of ettringite formation [54] and the generation of $\mathrm{Ca}(\mathrm{OH})_{2}$ [51]. It is, therefore, obvious that expansive pressure develops in SCDA is dependent on the degree of hydration of $\mathrm{CaO}$ in the demolition agent. The volumetric expansion in expansive cement is therefore caused by hydration of $\mathrm{CaO}$ producing $\mathrm{Ca}(\mathrm{OH})_{2}$, ettringite crystals and $\mathrm{CaSO}_{4}[40,48,55-58]$ leading to a gradual development of expansive pressures in the cement existing under a confinement.

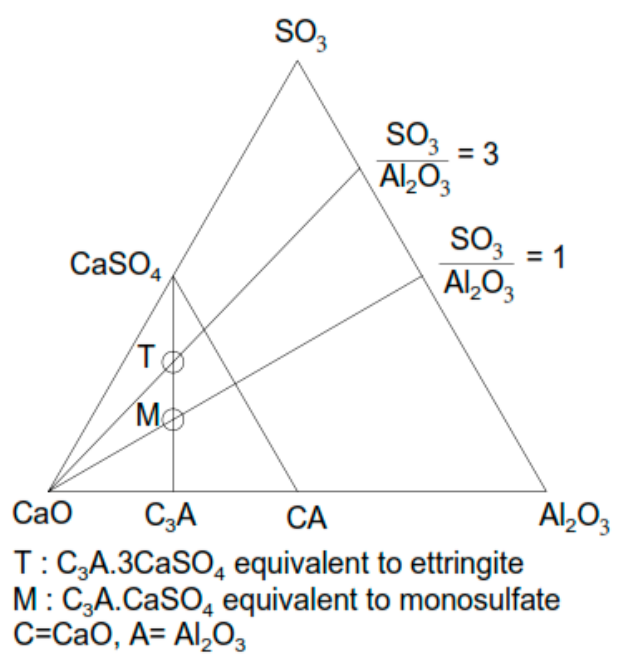

Figure 1. Expansive compounds present in cement [48]. 
However, volumetric expansion of SCDAs is mainly caused by the exothermic reaction of $\mathrm{CaO}$ under hydration as given by Equation (1) [34,40,56]:

$$
\mathrm{CaO}+\mathrm{H}_{2} \mathrm{O} \rightarrow \mathrm{Ca}(\mathrm{OH})_{2}+15.2 \uparrow(\mathrm{kCal} / \mathrm{mol})
$$

This reaction has been dominated in SCDA through controlling the $\mathrm{Al}_{2} \mathrm{O}_{3}$ content of the mixture (Table 2), which therefore results in a $\mathrm{CaO}$ hydration based expansion (Figure 1). Molar weight and specific gravity of $\mathrm{CaO}$ is 56 and 3.34 respectively and gives a volume of 17 the molar weight (74) and the specific gravity (2.24) of $\mathrm{Ca}(\mathrm{OH})_{2}$ gives a volume of 33 . Considering the mass volume relationship of $\mathrm{CaO}$ and $\mathrm{Ca}(\mathrm{OH})_{2}$, the volumetric change of $\mathrm{CaO}$ during hydration can be expected to be nearly 1.9 times, which is similar to the free volume expansion to two times in SCDA [37]. High concentrations of $\mathrm{CaO}$ in the liquid phase of the wet cement mix also increases the rate of formation of ettringite in the cement which further contributes to the volume expansion [59]. The hydration heat of the reaction could reach up to a temperature of $150{ }^{\circ} \mathrm{C}$ during the reaction, resulting in a generation of super-heated steam in the SCDA mixture. This, however, may vary under field conditions due to the possible heat dissipation into the surrounding environment [40]. A further volumetric expansion can be observed in SCDA by the formation of ettringite crystals (Equation (2)) which are formed at high concentrations of hydrated lime $[48,55,58]$ :

$$
4 \mathrm{CaO} \cdot 3 \mathrm{Al}_{2} \mathrm{O}_{3} \cdot \mathrm{SO}_{3}+8 \mathrm{CaSO}_{4} \cdot 2 \mathrm{H}_{2} \mathrm{O}+6 \mathrm{Ca}(\mathrm{OH})_{2}+74 \mathrm{H}_{2} \mathrm{O} \rightarrow 3\left(3 \mathrm{CaO} \cdot \mathrm{Al}_{2} \mathrm{O}_{3} \cdot 3 \mathrm{CaSO}_{4}+32 \mathrm{H}_{2} \mathrm{O}\right)
$$

\subsection{Quantification of Expansive Pressure Generation}

As mentioned, the expansive pressure is generated in SCDA as a result of confinement given by the surrounding materials. Elucidating the expansive mechanism of SCDA requires knowing the initial expansive pressure. To measure this initial expansive pressure of SCDA, to date many complex arrangements have been proposed by various researchers [37,60-62]. Harada et al. [37] developed three types of pressure transducers with similar performances; the outer pipe, inner pipe and diaphragm methods, which can be used to find the expansive pressure develop in the SCDA injected borehole. The outer and inner pipe methods were used as indirect methods to compute the expansive pressure. The strain $\left(\varepsilon_{\theta}\right.$, circumferential and $\varepsilon_{z}$, axial) generated on the surface of a steel pipe with the expansion of SCDA filled within the pipe was measured using strain gauges fixed to the outer pipe. In the inner pipe method, the strain gauges were attached to the inner surface of the pipe and the pipe was placed in a hollow concrete cylinder filled with SCDA. The expansive pressures generating in the outer and inner pipe methods are given by Equations (3) and (4), respectively [37]:

$$
\begin{gathered}
P=\frac{E\left(k^{2}-1\right)}{2\left(1-v_{s}^{2}\right)}\left(\varepsilon_{\theta}+v_{s} \varepsilon_{z}\right) \\
p=\frac{E\left(k^{2}-1\right)}{2\left(1-v_{S}^{2}\right) k^{2}}\left(\varepsilon_{\theta}+v_{s} \varepsilon_{z}\right)
\end{gathered}
$$

where, $E$ is Young's modulus of the steel pipe, $v$ is the Poisson's ratio of the steel pipe and $k$, is the ratio of outer diameter to the inner diameter. A pipe with sufficient thickness $(k)$ should be taken to adopt this method to avoid yielding of the material because the expansive pressure can only be calculated as long as the material deforms only in the linear elastic region. To measure the expansive pressure in narrow grooves the third method, known as the diaphragm method was introduced by Harada et al. [37] by using a diaphragm type transducer. The sensor required an initial calibration to be done prior to using in SCDA.

Using the outer pipe method, Hinze and Brown [41] conducted laboratory experiments to evaluate the performance characteristics of SCDA under three factors of water content, ambient temperature, and borehole diameter. The experiments were conducted by pouring expansive cement mixture into 
steel cylinders and the expansive pressure was calculated based on the principles of thick-walled cylinder theory [63]:

$$
P=\frac{E \varepsilon\left(r_{o}^{2}-r_{i}^{2}\right)}{2 r_{i}^{2}} .
$$

where, $E$ is the modulus of elasticity of the steel cylinder, $\varepsilon$ is the tangential strain on the outside of the cylinder and inside and outside diameter of the cylinder given by $r_{i}$ and $r_{o}$ respectively. The strain on the external surfaces of test cylinders was measured by a cluster of strain gauges located at mid-span of the cylinders.

\section{Factors Influencing the Performance of SCDA}

\subsection{Influence of Water Content and Degree of Hydration}

According to Hinze and Brown [41], the water content is inversely proportional to the expansive pressure generating in SCDA inside a confined volume (as they used a thick cylinder with an inner diameter of $25 \mathrm{~mm}$ ). A $4 \%$ increase in water content showed a pressure decrease of $22 \%$ and $23 \%$ in ambient temperatures of $22{ }^{\circ} \mathrm{C}$ and $34^{\circ} \mathrm{C}$, respectively in SCDA (Figure 2). This negative influence creating by water content on the expansive pressure in SCDA has later been confirmed by many researchers [38,51].

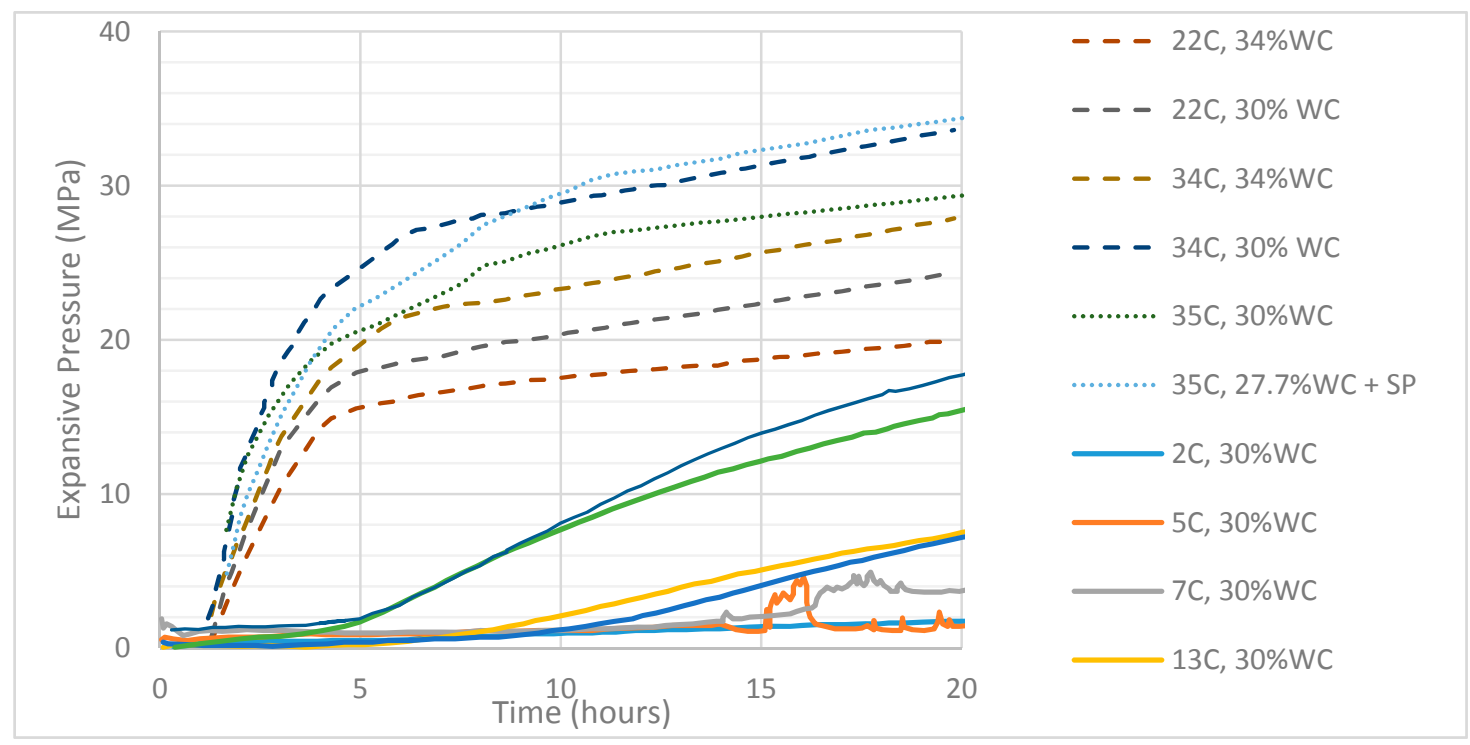

Figure 2. Variation of expansive pressure of SCDA with moisture content and ambient temperature $[38,40,61]$.

Following the work of Hinze and Brown [41], Hinze and Nelson [38] conducted experiments to improve the performance of SCDA by further reducing the manufacturer recommended minimum water content of $30 \%$. The water content was reduced to $27.7 \%$ and the workability of the mix was maintained by using $0.0132 \mathrm{~mL} / \mathrm{g}$ dose super-plasticizer. The results obtained for tests conducted at $35{ }^{\circ} \mathrm{C}$ are shown in (Figure 2), which clearly shows the negative influence created by the water content on SCDA expansive pressure generation. Results of SCDA with $30 \%$ moisture content at $34{ }^{\circ} \mathrm{C}$ [41] showed a higher rate of pressure generation compared to the results of Hinze and Nelson [38] due to the difference in bore sizes used. According to Hinze and Nelson [38], reduction of SCDA water content, however, only causes a marginal increment in the expansive pressure at the expense of additional material. As far as rock fragmentation is concerned, reduced Water content will only reduce the demolition time slightly and may not be desirable in an economic point of view. 
This expansive pressure of SCDA is directly related to its composition, particularly its major compound $\mathrm{CaO}$. Variation of expansive pressure, $\mathrm{P}(\mathrm{MPa})$ with the degree of $\mathrm{CaO}$ hydration, $\mathrm{h}(\%)$ has therefore been modelled by Harada et al. [37] (for a certain water content of 25\%) as given by Equation (6) and illustrated in Figure 3. Here, the degree of hydration has been written as a function of the degree of $\mathrm{CaO}$ hydration, $h(\%)$, which is a time $(t)$ and temperature dependent parameter Equation (7) at $20^{\circ} \mathrm{C}$ and Equation (8) at $30^{\circ} \mathrm{C}$. This exhibits the significant influence created by the temperature of the expansive pressure and its variation over time:

$$
\begin{gathered}
P=128.9\left(\frac{h}{100}-0.14\right)^{1.68} \\
\frac{h}{100}=t /(10.6+1.55 t) \\
\frac{h}{100}=t /(8.65+1.02 t)
\end{gathered}
$$

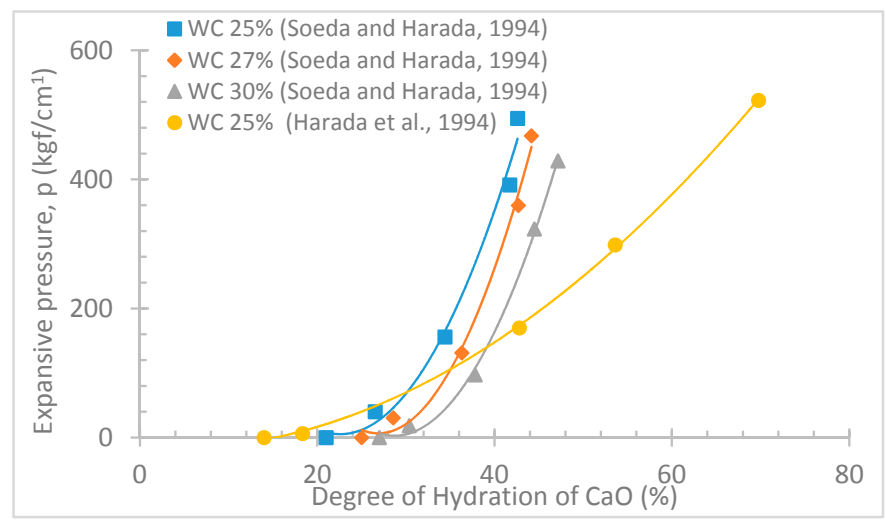

Figure 3. Variation of expansive pressure generated with degree of hydration $[37,51]$.

An extension of this study was carried out by Soeda and Harada [51] by changing the water content of SCDA. They found that the expansive pressure generated in SCDA is not only $\mathrm{Ca}(\mathrm{OH})_{2}$ quantity dependent but also it is $\mathrm{Ca}(\mathrm{OH})_{2}$ concentration dependent (Figure 3), where at higher water contents a larger degree of hydration is found to be required in SCDA to produce a particular expansive pressures, which will be more comprehensively explained in a later section (volume expansion mechanism of SCDA). As shown in Figure 3, there is a significant deviation in the relationship between the degree of hydration and the expansive pressure of SCDA between the results interpreted by Harada et al. [37] and Soeda and Harada [51]. This may be due to the difference in how the content of $\mathrm{Ca}(\mathrm{OH})_{2}$ was calculated at $100 \%$ hydration of SCDA was obtained. The $\mathrm{Ca}(\mathrm{OH})_{2}$ content of SCDA at $100 \%$ hydration was obtained by steam curing for 3 days by Harada et al. [37], whereas no specific information on how the content of $\mathrm{Ca}(\mathrm{OH})_{2}$ at the end of hydration is given by Soeda and Harada [51].

\subsection{Influence of Ambient Temperature}

Hinze and Brown [41] found that ambient temperature is directly proportional to the expansive pressure generated (see Figure 4) in SCDA up to a certain threshold value, after which blowout of SCDA may occur. Similar results have been reported by Harada et al. [37] and Natanzi et al. [40], in which studies blowout of SCDA occurred as a result of elevated hydration heat. According to Harada et al. [37] and Natanzi et al. [40], at high ambient temperatures (19-30 $\left.{ }^{\circ} \mathrm{C}\right)$, noticeable temperature peaks can be generated in SCDA sometime after the pouring $(4 \sim 5 \mathrm{~h})$ simultaneously with steep pressure rises (Figure 4a). The temperature spike is often followed by sudden increasing of expansion pressure (Figure $4 \mathrm{~b}$ ). This pressure increment rate is found to be temperature dependent, 
which increases with increasing temperature, and the behavior could be attributed to the accelerated $\mathrm{CaO}$ hydration at higher temperatures.

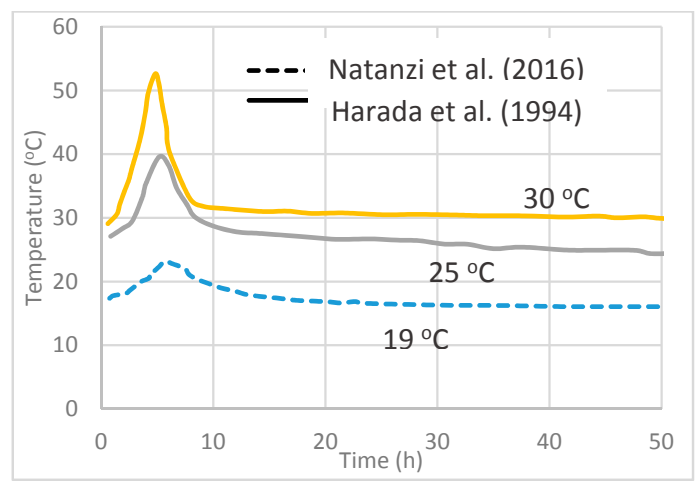

(a)

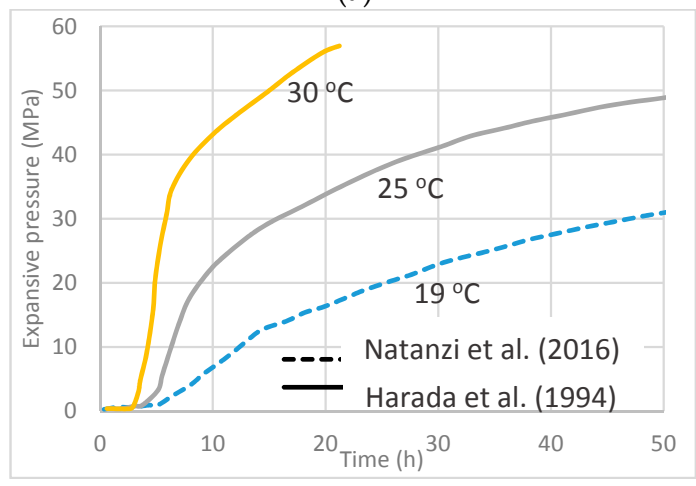

(b)

Figure 4. Effect of ambient temperature on expansive pressure (a) Temperature variation of SCDA with time; (b) Expansive pressure variation of SCDA with time [37,40].

This temperature influence on SCDA expansive pressure development has been comprehensively studied by Natanzi et al. [40] using two commercially available SCDAs (Dexpan and Bristar) in a $36 \mathrm{~mm}$ internal diameter steel pipe under a range of temperatures (low to moderate ambient temperatures). This approach is similar to the procedure adopted by Brown and Hinze [41] and therefore can confidently be compared. Figure 2 shows the results obtained by Natanzi et al. [40] for SCDA Bristar brand and according to that the characteristics of expansive pressure development of SCDAs under low and high ambient temperatures are clearly different. At higher temperatures an intense pressure development can be seen within the first $5 \mathrm{~h}$ and under lower temperatures significant pressure development can be seen after $10 \mathrm{~h}$. Further, with a small temperature variation from $19^{\circ} \mathrm{C}$ to $21^{\circ} \mathrm{C}$ a sudden change in expansive pressure development was occurred (pressure rose from $2 \mathrm{MPa}$ to $19 \mathrm{MPa}$ after $3 \mathrm{~h}$ ) causing "blowout" of SCDA. This is mainly due to the failure of surrounding material to dissipate heat under high temperatures [41]. Results of Natanzi et al. [40] show the nonlinearity relation of SCDA pressure development with ambient temperature. However, elevated temperatures may not be a critical factor for blowout in the field, as heat can be easily dissipated through the surrounding rock in underground.

\subsection{Influence of Borehole Diameter}

Though findings show the influence created by borehole diameter is not significant in long-term $(24 \mathrm{~h})$ expansive pressure in boreholes [41], the rate of expansive pressure development increases with increasing borehole diameter [36,41]. In this regard, Dowding and Labuz [64] found the effect of borehole diameter to be negligible on the final expansive pressure at $24 \mathrm{~h}$ by conducting a series of tests using boreholes with varying diameters. However, they did observe the greater rate of expansive 
pressure increment in larger diameter boreholes $(50 \mathrm{~mm})$ compared to smaller $(25 \mathrm{~mm})$ ones. This direct relation of bore diameter on expansive pressure development rate can be explained by the hydration reaction of $\mathrm{Ca}(\mathrm{OH})_{2}$, the common compound in SCDA. Larger diameter holes enable an increase mass of free lime to be hydrated in the borehole. The initiating exothermic reaction increases the temperature of SCDA accelerating the hydration process compared to SCDA filled in smaller boreholes. This confirms that increasing borehole diameter increases the temperature of SCDA, which indirectly relates to the increased degree of hydration, the main determinant of creating SCDA expansive pressure in a confined space [51]. According to Hinze and Brown [41] and Dowding and Labuz [64], irrespective of the rate of the expansive pressure generating in different borehole sizes, the long-term expansive pressure converges to a steady value over time. This maximum expansive pressure is generated with the completion of hydration reaction of $\mathrm{CaO}$ after a significant time. This implies that the changing of borehole diameter will only increase the rate. However, when interpreting this information in the context of rocks, the possible final expansive pressures variation with borehole size should be considered, because a reduction in confinement may be caused by varying elasticity moduli of different rocks. For a rock with a large modulus of elasticity, SCDAs can generate high pressures while for weaker rocks the expansive pressure will be lower [34].

\section{Volume Expansion Mechanism}

In order to explain the mechanism for expansive cement, the swelling theory, and the crystal growth theory are commonly used in the field [65]. The First theory suggests expansion is caused by the water adsorption and corresponding swelling characteristics of the hydrating particles and the latter suggests expansion is caused by the growth of the particles through reacting them with the surrounding solution containing sulfates hydroxides and water. Ghosh [59] relates these two mechanisms to understand the volume expansion occur in SCDA, through using crystal growth theory to explain the formation of hexagonal prism crystals of $\mathrm{Ca}(\mathrm{OH})_{2}$ and swelling theory to explain the formation and elongation of $\mathrm{Ca}(\mathrm{OH})_{2}$ microcrystals around hydrating $\mathrm{CaO}$. Expansion in SCDA was obtained within a short period of time primarily with hydrating free lime in a cement mixture.

The expansive pressure generating mechanism in $\mathrm{CaO}$ type expansive cement has been explained using a new mechanism by Chatterji [56], in which the wet cement paste is said to be saturated with the diffusion of $\mathrm{Ca}^{2+}$ and $\mathrm{OH}^{-}$ions forming an alkali solution around the hydrating $\mathrm{CaO}$ particles. Initially very fine $\mathrm{Ca}(\mathrm{OH})_{2}$ crystals $(10 \sim 20 \mathrm{~nm})$ with high solubility are formed in the solution, which subsequently recrystallizes into larger crystals. The larger crystals then grow-up around the hydrating $\mathrm{CaO}$ particles at the expense of smaller crystals. When the particle growth is restrained an outward thrusting pressure is generated, which is commonly known as the crystal growth pressure, $\Delta \mathrm{P}$, and is given by:

$$
\Delta \mathrm{P}=\frac{\mathrm{RT}}{\mathrm{V}_{\mathrm{m}}} \ln \left(\frac{a_{s}}{a_{o}}\right)
$$

where, $V_{m}$ is the molar volume of the $\mathrm{Ca}(\mathrm{OH})_{2}$ crystal, $\mathrm{R}$ is the gas constant, $\mathrm{T}$ is the absolute temperature, $a_{s}$ and $a_{o}$ are the mean activity of the supersaturated and saturated solutions respectively. According to this theory, a larger volume expansion can be expected in the presence of large $\mathrm{CaO}$ particles because a larger volume of hydroxide crystals can enclose the particle [56]. However, contradictory to this claim a quicker reaction could take place if smaller particles of $\mathrm{CaO}$ were present, due to the increased surface area for the reaction.

The effect of moisture content on expansive pressure development is also critical. The requirement of higher degree of hydration in the presence of greater water contents [51] has been explained by Shalom's spherical model $[55,57,66]$. The mechanism described here has a close resemblance to the explanation given by Chatterji [56], which also explains the large pressure increments occur in SCDAs in the presence of lower moisture content. As shown in Figure 5 hydration of $\mathrm{CaO}$ results in the growth of solid particles, which come into contact with each other at a point, known as the critical degree of hydration. Beyond this point, further growth of solid particles results in the generation of 
expansive pressure under a confined condition. At lower water contents, a larger particle density $\left(D_{1}>D_{2}\right.$, Figure 5$)$ is occurred producing smaller distances between neighboring particles [51] and therefore, a lower degree of hydration brings particles into contact enabling early generation of expansive pressures in SCDAs.

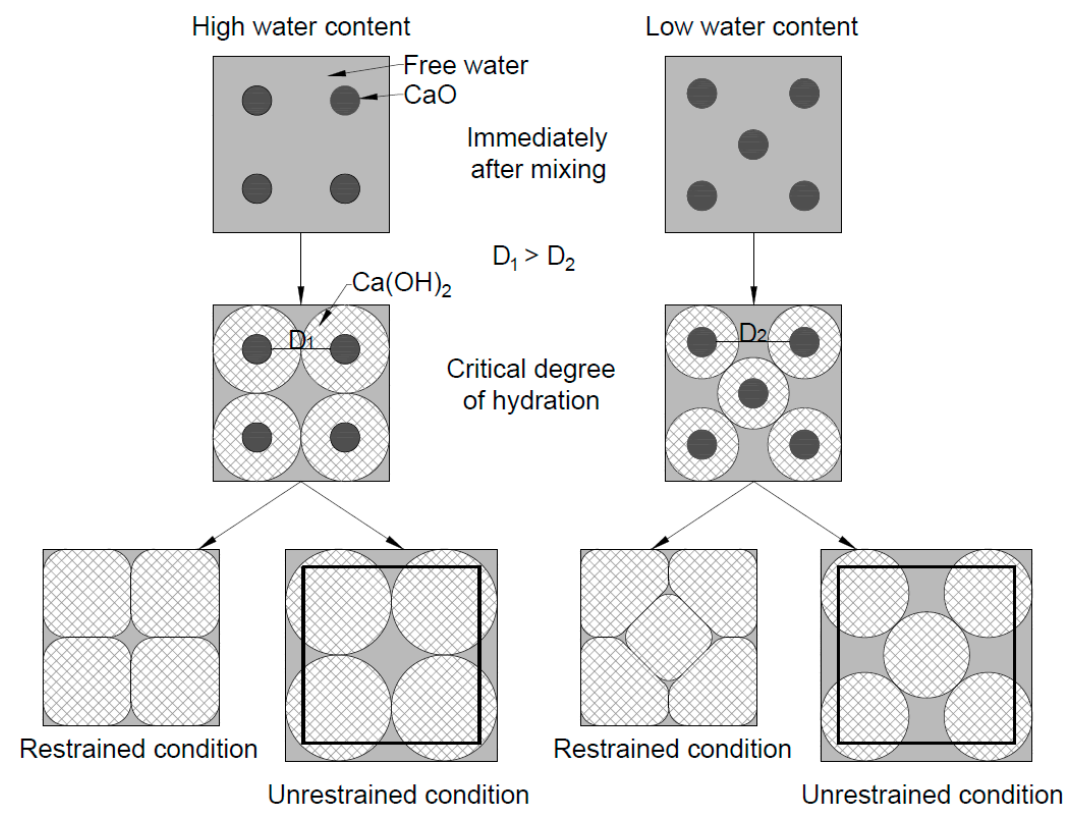

Figure 5. Shalom's sphere model for expansive mechanism of $\mathrm{Ca}(\mathrm{OH})_{2}[66]$.

The other additives are normally added in various mixing proportions to alter the hydration of SCDA and depending on the type of SCDA the expansive pressure from chemical hydration can be varied in-between $15 \mathrm{~min}$ to $24 \mathrm{~h}$ [41]. The effect of such additive on the expansive pressure is, therefore, worth to examine. According to Dessouki et al. [35], the addition of $15 \% \mathrm{CaSO}_{4}$ to SCDA (Betonamit brand) significantly accelerates its volumetric expansion rate, though the maximum expansion is reached at a later stage. Based on the literature of expansive cement, it is evident that the volumetric expansion of expansive cement results from the combined effect of ettringite (a hydrous calcium aluminum sulfate mineral) formation and $\mathrm{CaO}$ hydration. In addition to the chemical strength, increasing the particle fineness also accelerates the hydration process [67]. Because of this reason, the fineness of the SCDA used in experiments of Soeda and Harada [51] were in the order of $2200 \sim 3000 \mathrm{~cm}^{2} / \mathrm{g}$, which is similar to the fineness of C-S-A type and CaO type cement.

\section{Soundless Chemical Demolition Agent Generated Crack Propagation}

One important thing in determining the applicability of SCDA in rock fragmentation is the fracturing mechanism of the rock, fracture initiation, and propagation, under the expansive pressure generation by SCDA. This fracturing mechanism of rock under SCDA charging has not been studied by many, and the lack of knowledge on SCDA controlled fracturing process in rock is one of the main causes to its poor market value. Unlike other fracturing methods (hydro-fracturing and explosives), SCDAs may exhibit high versatility with controlled crack formation. A desired propagation of the fracture network could be achieved by altering the size and spacing of boreholes and their arrangements [60]. The fracturing mechanism through SCDA is related with the hydro-fracturing process of rocks. Hydraulic fracturing can produce a single fracture splitting the sample into two; whereas multiple radial fractures can be observed around the injection well, where usage of SCDA instead of high-pressure fracturing fluid has the ability to produce a superior network of fractures (Figure 6). Fracture models that can be used for rock fragmentation through SCDA offer valuable knowledge on understanding this enhancement of fracture network through SCDA. 


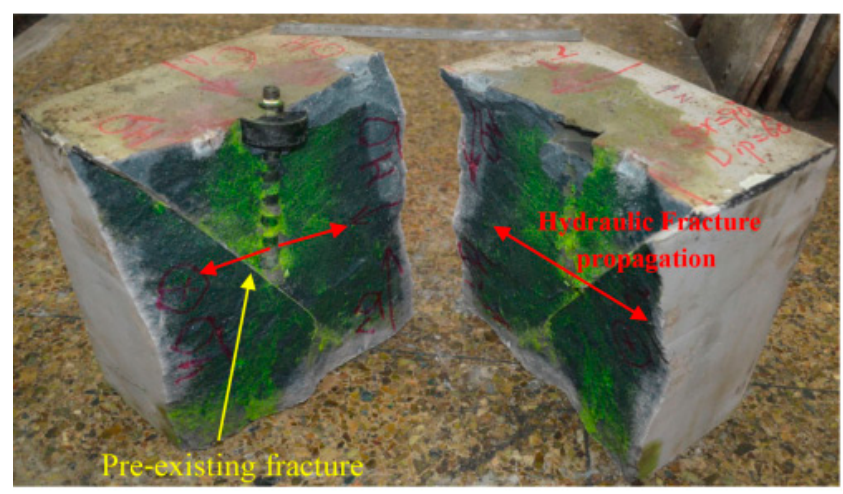

(a)

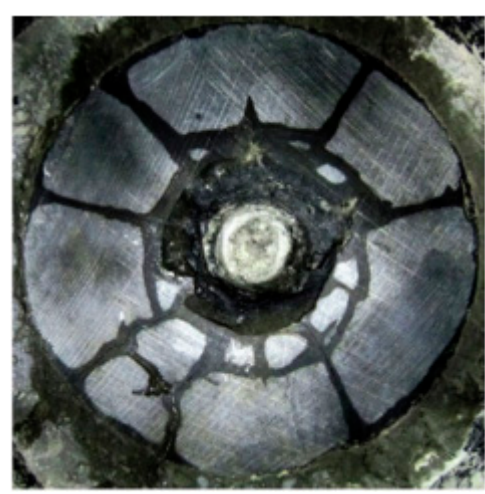

(b)

Figure 6. Crack pattern comparison (a) a single crack in hydraulic fracturing [68]; (b) multiple radial fractures with SCDA [69].

The failure mode of rock under any mechanism of failure is mainly governed by the temperature and the confinement pressure of the subjecting rock. Ductile failures can be occurred in common rocks in underground as sandstone and non-porous silicate rocks at very high confinement pressures (at $100 \mathrm{MPa}$ and $400 \mathrm{MPa}$ ) [70,71], whereas the effect of temperature on ductile behavior of non-porous silicate rocks can be caused by melting at grain boundaries at high temperatures $\left(>600{ }^{\circ} \mathrm{C}\right)$ [72]. Such conditions may prevail in the rock condition at deep depths of more than $5 \mathrm{~km}$. However, possible practical application of SCDA conditions may not reach such extreme conditions and therefore it is sufficient to explore the failure mechanisms associated with brittle failure of rock, which can more easily be used to explain fracture mechanics of rock under SCDA charging.

\subsection{Brittle Failure of Rock}

Brittle failure nature of rock has been extensively investigated in the field [73-80] and five major failure regions have been shown (Figure 7). Among them, region I represent the pre-existing cracks close stage in the rock mass, which is dependent on the geometry and the density of microcracks in the rock mass. The closing of the pre-existing cracks enables the rock to be presumed as a damage free linear elastic material having a linear stress-strain relation (Region II) [77]. This elastic region is followed by a non-linear stress variation region in rock, which consists of a combination of random crack formation, crack growth, and sliding of existing crack faces [81]. Region III or stable crack growth region comes next [77], which normally begins when the stress level is around 50\% of the peak strength of the rock mass or at the onset of dilation (Figure $7 \mathrm{~b}$ ).

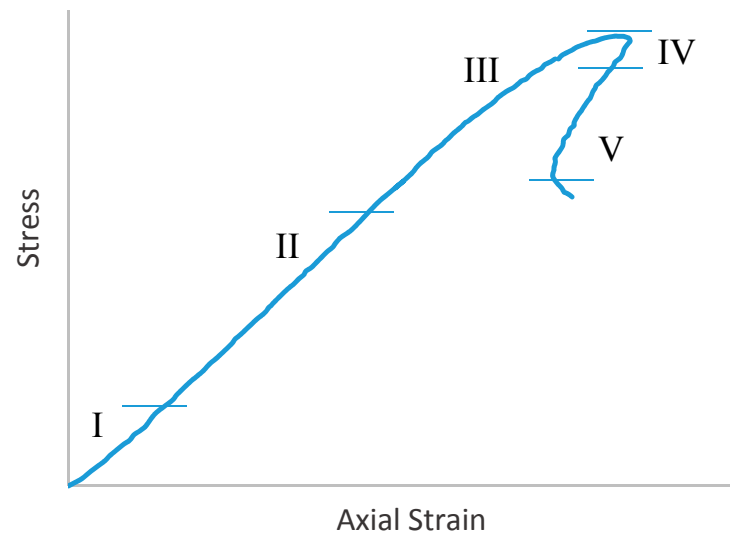

(a)

Figure 7. Cont. 


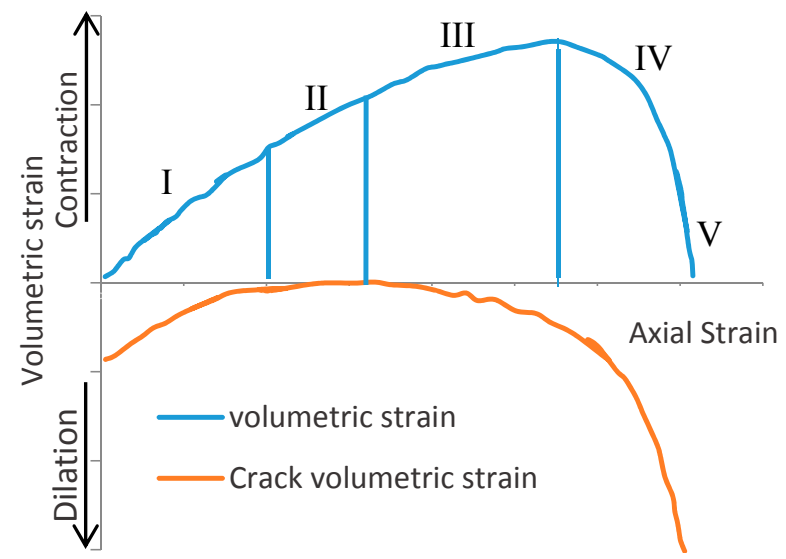

(b)

Figure 7. (a) Typical stress-axial strain development of rock under brittle failure [80]; (b) Variation of volumetric strain with Axial strain under brittle failure [77].

This crack growth happens parallel to the maximum applied load direction and requires a greater applied load for a further propagation, which therefore does not necessarily cause a strength reduction in the material $[77,80]$. This phenomenon will be further discussed in fracture models later on in this section. However, increasing density of cracks eventually leads to a point at which crack propagation becomes unstable, which is the starting point of the Region IV, unstable crack propagation. At this stage, the strain is increased with creating sliding faces of formed cracks. A further increase of load causes a temporary strain hardening effect with resulting subsequent failure. Figure $7 \mathrm{~b}$ illustrates the definition of stress regions under brittle failure of rock with respect to the total volumetric strain, $\varepsilon_{v o l}$ and the crack volumetric strain, $\varepsilon_{\text {crack }}$ obtained by Equations (10) and (11), respectively:

$$
\begin{gathered}
\varepsilon_{\text {vol }}=\varepsilon_{\text {axial }}+2 \varepsilon_{\text {lateral }} \\
\varepsilon_{\text {crack }}=\varepsilon_{\text {vol }}-\frac{1-2 V}{E}\left(\sigma_{1}-\sigma_{3}\right)
\end{gathered}
$$

Depending on the applied stress condition, the rock failure has been divided into three major modes in the literature [82]. It is, however, evident that the failure of rocks is dependent on its ability to resist crack propagation and therefore assessment of rock fracture toughness has been the basis for most of the up to date fracture models. Fracture toughness is, therefore, one of the fundamental material properties that have been used in developing rock fragmentation models. Out of the main modes of crack propagation that consist of a tensile crack opening, shearing and tearing (Figure 8), rock fragmentation using SCDA predominantly causes tensile (mode I) failure due to the hoop stresses developing around the injection well. The stress intensity factor is used to describe the state of stress fields at a crack tip which is used to establish the failure criteria of a material caused by fracturing [83]. Depending on the mode of failure as shown in Figure 8, the stress intensity factor is defined for tensile (Mode I) and shear (Mode II) failure. Since fracturing is initiated by the tensile failure of rock, stress intensity factor in mode 1 failure $\left(\mathrm{K}_{\mathrm{I}}\right)$ can be used to explain the deformation characteristics at the crack tip [84]. In addition, fracture nucleation is assisted by micro cracks oriented at an angle to the direction of radial compression, which is an effect of shearing (mode II). Thus, damage mechanics models developed with mode I and mode II stress intensity factors ( $\mathrm{K}_{\mathrm{I}}$ and $\mathrm{K}_{\mathrm{II}}$ respectively) will be discussed in this paper in an attempt to find their suitability to assess SCDA assisted rock fragmentation. 


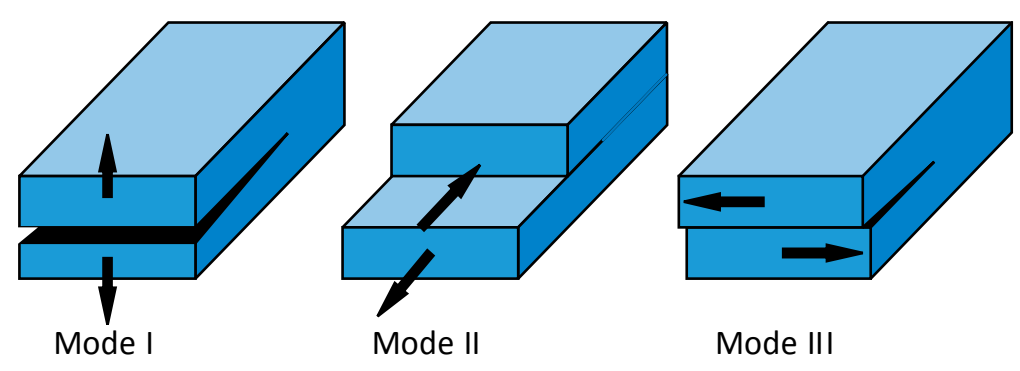

Figure 8. Modes of crack propagation.

\section{Quasi-Static Fracture Propagation}

The expansive pressure generated by SCDA in a borehole develops compressive stresses in the radial direction and tensile stresses tangential to the borehole creating a fracture at a point located on the inside surface of the hole with minimal confinement [40] (Figure 9).Though initial cracks appear at the surface of the borehole when the tangential stress reaches the tensile strength of the rock, crack propagation may not occur, because instantaneous tensile stress at crack tip does not exceed the tensile strength of the rock. This is because the applied tangential stress $\left(\sigma_{\theta}\right)$ reduces with the distance to the borehole (in proportion to the square of the distance) [5].



Figure 9. Fracture propagation from borehole (modified after Harada et al. 1989).

The mode I stress intensity factor in internally pressurized thick walled vessels (where the internal pressure does not reach the crack tip) can be used to explain the stable crack growth of rock when fractured with SCDA. The fracture propagation of cylindrical rock specimens with the ratio of the outer diameter to the inner diameter (Borehole drilled in the centre of the specimen), $\mathrm{k}$ greater than 5 was observed by Harada et al. [5] to study this. Shown in Figure 10 is the variation of Stress intensity Factor $\mathrm{K}_{\mathrm{I}}$ with increasing crack length along the wall of a jacketed cylinder. For vessels with $\mathrm{k}>5$, after reaching an initial peak, the value of $\mathrm{K}_{\mathrm{I}}$-crack length curve exhibits a negative slope exhibiting an additional pressure requirement for a further crack development. Thus, a stable crack growth with increasing pressure can be observed. It is clear that at $\mathrm{L}=0.05$ the stress intensity of the fracture in the cylinder exhibits a reducing trend with increasing thickness ratio $\mathrm{k}$. The tests were conducted by increasing for a cylinder with an internal jacket [85]. Thus, the increasing fluid pressure within the borehole does not directly apply a pressure on the propagating crack tip in the cylinder as opposed to an unjacketed situation. This replicates the conditions when SCDA is used in a borehole. When the cylinder has a substantial thickness, the stress intensity at the crack tip diminishes as the crack propagates (beyond $\mathrm{L}=0.05$ ), but when the thickness of the cylinder is less (i.e., $\mathrm{k}<5$ ) the stress intensity factor increases with increasing crack length $L$ leading to unstable crack growth. 


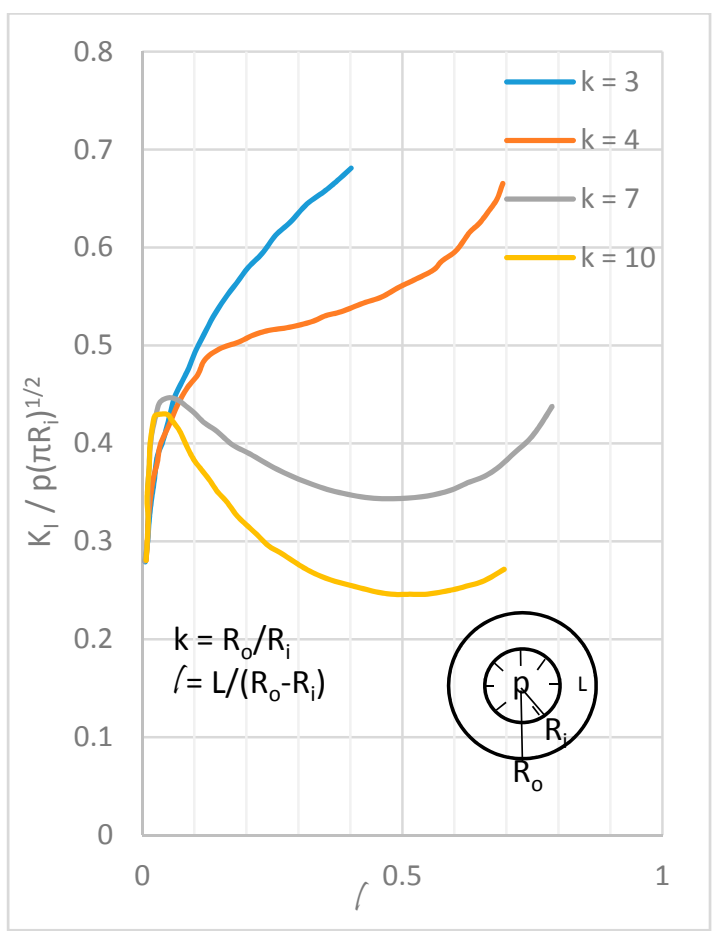

Figure 10. Variation of Stress Intensity Factor with respect to crack length [85].

The expansive pressure generating by SCDA results from the confinement given by the surrounding rock. Initiation of a fracture indicates a release of confinement of the rock and a resulting drop in expansive pressure can be observed. An Idealized pressure plot that explains this stable crack growth behaviour is shown in Figure 11, in which $P_{o}$ and $t_{o}$ correspond to the initial crack caused by SCDA expansive pressure drop occurs during the cracks propagation. The fracture is propagated only when the tensile stress applied is increased by SCDA expansion.

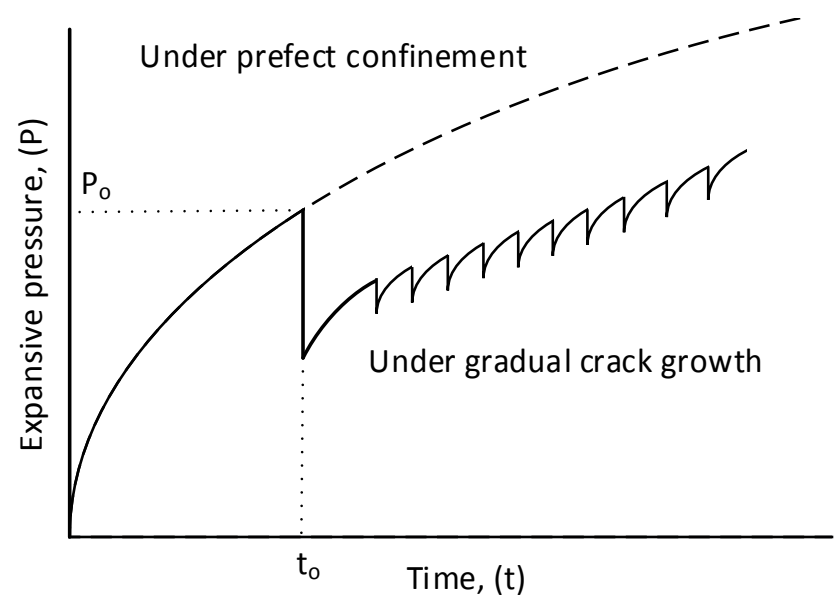

Figure 11. Possible pressure growth with time [64].

Thus, unlike in hydraulic fracturing, in which fracturing is observed instantaneously as a result of hydraulic pressure directly acting on the crack tip, in SCDA cracking a stable crack growth can be expected. Figure 12 illustrates the possible crack growth states in some rock materials. Because stable crack propagation with low crack velocities can be observed when fracturing rock with SCDA, the quasi-static conditions can be assumed in fracture modelling. 


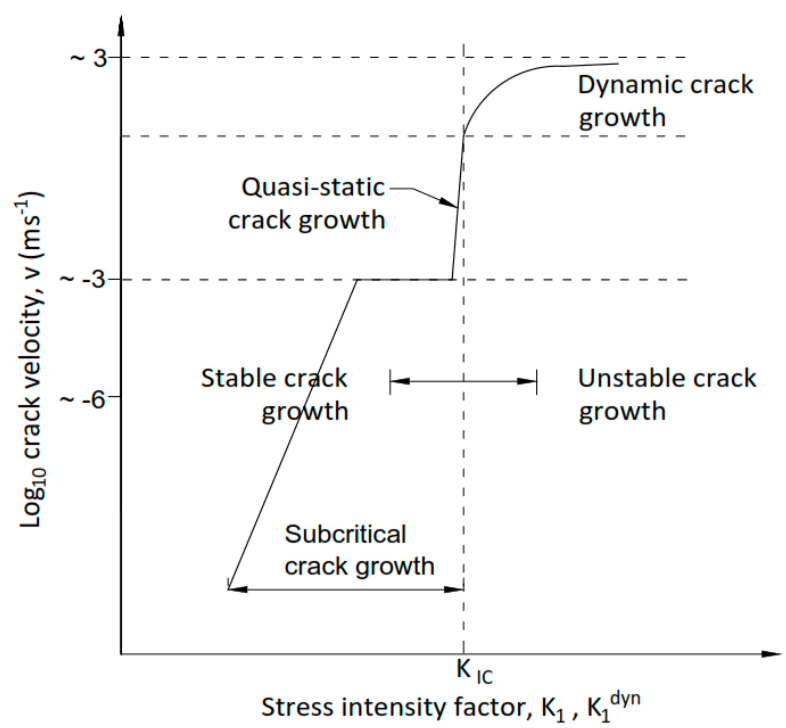

Figure 12. Crack growth states in rock materials. Subcritical crack growth after Atkinson [86], Lockner and Madden [86,87] and dynamic crack growth, after Bieniawski [88].

\subsection{Modelling of SCDA Creating Damage Mechanism}

There are many damage mechanism models using in rocks, such as continuum damage mechanisms models, micromechanics-based constitutive fracture models and micro crack based sliding crack models. However, the applicability of them for SCDA-based rock fragmentation is questionable and only the micro crack based sliding crack models are likely to be applicable.

\section{Microcrack Based Sliding Crack Models}

The expansive pressure developing by hydrating SCDA in an injection well produces radial compressive stresses in the surrounding rock along with tangential hoop stresses. The rock surrounding the injection well is assumed to be fragmented as a result of pre-existing micro crack extension in the presence of these two stress fields. As a result, the mechanism of fracturing rock with SCDA can be best explained by using sliding crack models.

A simple 2D sliding crack model has first been proposed by Brace and Bombolakis [89]. According to this, present cracks in any brittle material extend along a curved path that eventually becomes parallel to the compression axis. Such crack extensions are known as kinks or wing cracks. An initial crack growth model for the extension of wing cracks has been proposed by Kachanov [90] under a compressive stress field by modelling the crack growth with respect to the applied pressure normal to growing wing crack (Table 3). The wing crack was assumed to be initiating from the crack tips of pre-existing microcracks due to the frictional sliding Kachanov [91].

In 1982, Nemat-Nasser and Horii [92] experimentally found the possibility of existing nucleation and propagation of tensile cracks at the tips of existing cracks. Nemat-Nasser and Horii [93] conducted uniaxial compression on plates of a brittle material to investigate the behaviour of a pre-existing planar crack set when it at different orientations to the major principal stress $\left(\sigma_{1}\right)$. The frictional sliding $(\tau)$ between the faces was found to produce wing cracks at crack tips, which deviate sharply from the sliding plane and continue to grow steadily towards the axis of major principal stress with increasing compressive strength (see Figure 13). The results are consistent with the basic equation produced by Kachanov [90], according to which the stress required for crack growth increases with increasing length of the wing crack. Results of Nemat-Nasser and Horii [92] was later used in many models as the crack initiation mechanism [94-96]. They observed an increasing crack growth after a certain length of the wing crack, which is found to be further accelerated if a tensile stress existed normal to the crack growth direction. According to Ashby and Hallam [97], the existence of a negative confinement ratio 
( $\left.R=-\sigma_{3} / \sigma_{1}\right)$ may result in unstable crack propagation, because the major principal stress required for crack growth reduces with increasing normalized crack length, 1/c (Figure 14). This confirms that accelerated crack propagation in the presence of a far field tensile stress. For the case of expansive pressure generated by SCDA, radial compressive stresses and tensile stresses tangential to the borehole circumference can be observed (Figure 9). Crack growth may occur either radially or in a curved path assisted by tangential hoop stresses applied in the crack opening direction. This implies the possibility of using Nemat-Nasser and Horiis' [92] plane strain model to describe the failure mechanism of SCDA fracking.

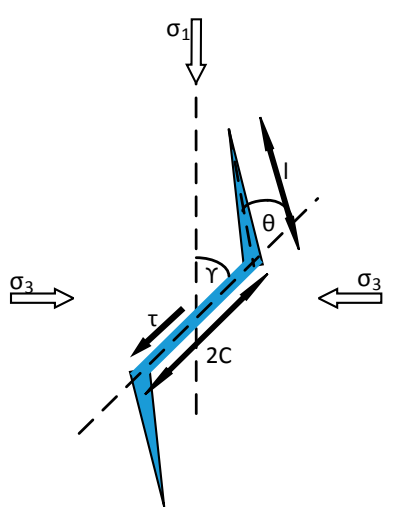

(a) Nemat-Nasser and Horii (1982)

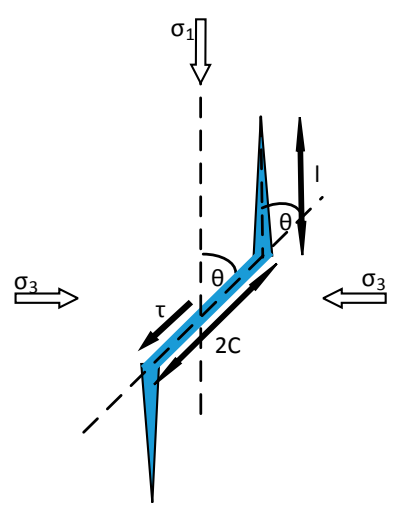

(b) Ashby and Hallam (1986)

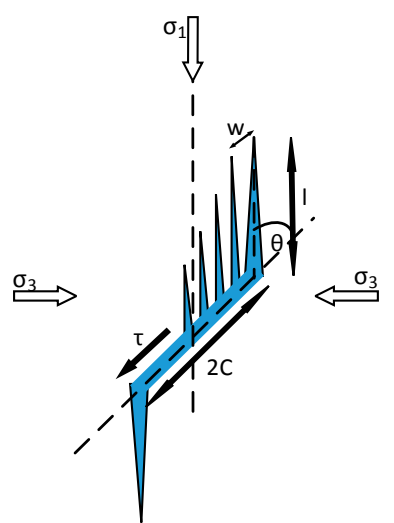

(c) Renshaw and Schulson (2001)

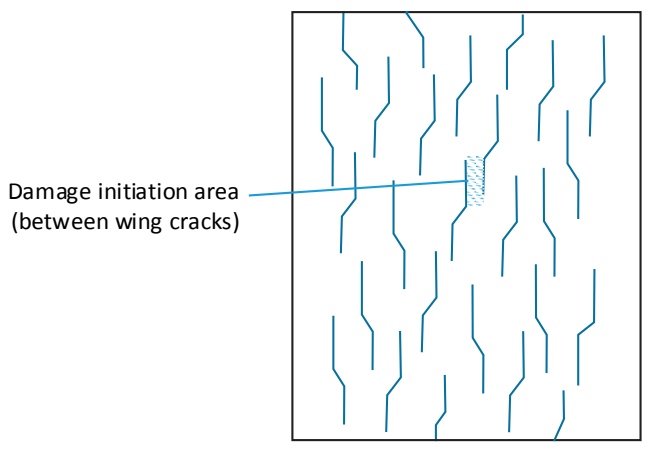

(d) Ashby and Hallam (1986)

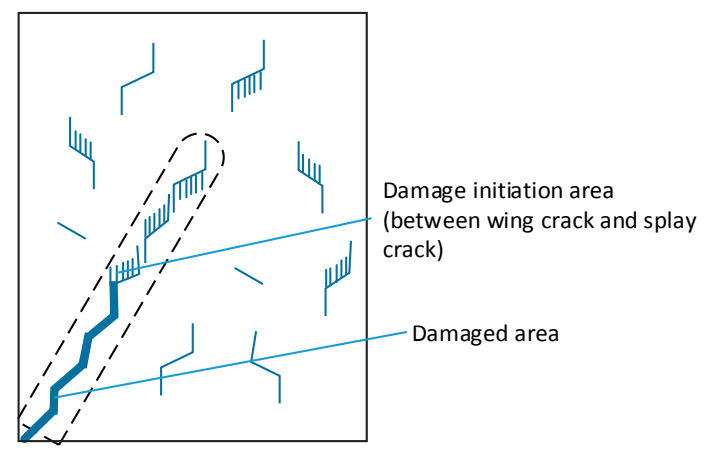

(e) Schulson et al. (1999)

Figure 13. Simple 2D microcrack models developed [92,95-97]: (a) Nemat-Nasser and Horii wing crack model [92]; (b) Ashby and Hallam wing crack model [97]; (c) Renshaw and Schulson wing crack model [95]; (d) Failure mechanism proposed by Ashby and Hallam [97]; (e) Failure mechamism proposed by Schulson [96].

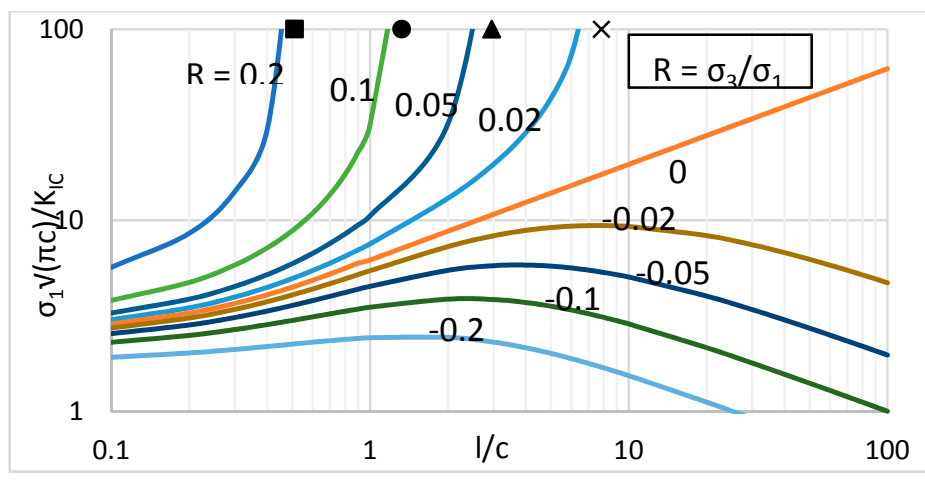

Figure 14. Wing crack growth $(1 / \mathrm{c})$ variation with confinement ratio. Crack arrest lengths of Renshaw and Schulson (R-S) [95] and Ashby and Hallam [97]. 
A similar model has been developed by Ashby and Hallam [97] by considering the mode 1 failure of brittle materials. The model exhibits similar characteristics with Nemat-Nasser and Horii [92] (Figure 13a,b), that overcome one important weak point of Nemat-Nasser and Horii [92] model, which does not account the influence of microcracks coalescence existing in the material for crack propagation. However, according to Rose [98] and Atkinson [84], crack extension in the rock-like material is caused by progressive linking of micro cracks. Thus, the microcrack nucleation and propagation model was extended by Ashby and Hallam [97] and Ashby and Sammis [99] to elucidate the mechanism of crack interaction that leads to a macroscopic failure. According to the model, extension of wing cracks up to neighbouring micro cracks in an array of micro cracks divides the solid into microcolumns, which become slender with the growth of wing cracks. This allows the resultant forces to be treated as axial forces, shear forces and bending moments acting on the column. Provided that the network of fractures are uniformly distributed, the failure of the material can be analysed with a single column (Figure 13d). The governing equations for stress intensity factor including the effect of micro crack interaction are shown in Table 3.

Table 3. Sliding wing crack models.

\begin{tabular}{|c|c|c|}
\hline Refs. & Governing Equation & Remarks \\
\hline [90] & $\begin{array}{l}\qquad \sigma^{\prime}=k \frac{\tau}{\sqrt{2 c / l}}-\frac{K_{I C}}{\sqrt{\frac{\pi}{2} l}} \\
\sigma^{\prime}=\text { Stress acting normal to wing crack resulting from the major and minor principal stresses }\left(\sigma_{1}, \sigma_{2}\right) \\
l=\text { wing crack length } \\
2 c=\text { initial flaw length } \\
\tau=\text { Shear stress on the crack surface resulting from } \sigma_{1} \text { and } \sigma_{3} \text { (Figure 13 Simple 2D } \\
\text { microcrack models) } \\
k \approx 1.15 \text { (variable) }\end{array}$ & $\begin{array}{l}\text { The basic model developed by } \\
\text { including the length of wing } \\
\text { crack to determine the crack } \\
\text { growth stress. }\end{array}$ \\
\hline [92] & $\begin{array}{l}\qquad \sigma_{1}=\frac{\sqrt{3} k_{I C}}{\sqrt{\pi c}\left[R\left(\sqrt{1+\mu^{2}}+\mu\right)-\left(\sqrt{1+\mu^{2}}-\mu\right)\right]} \\
\text { Crack initiation stresses given when the length of the wing crack is zero }\end{array}$ & $\begin{array}{l}\text { 2D model for crack initiation } \\
\text { from pre-existing } \\
\text { micro-fractures in the material. } \\
\text { Sliding of crack faces causes } \\
\text { mode } 2 \text { failure in crack tip } \\
\text { initiating wing cracks. }\end{array}$ \\
\hline [99] & $\begin{array}{l}\qquad \sigma_{1}=\frac{K_{I, 1} / \sqrt{\pi a}}{-L^{\frac{1}{2}}\left\{\frac{1.1(1-2.1 R)}{(1+L)^{3.3}}-R\right\}} \\
\text { Stress intensity factor from a single crack } \\
\qquad \sigma_{1}=\frac{K_{I, 2}}{-\frac{\sqrt{2}}{\pi} f_{A}^{\frac{1}{2}}(L+1)^{\frac{1}{2}} \sigma_{1} \sqrt{\pi a}\left\{\left[1-\frac{8}{\pi} f_{A} R(L+1)^{3}\right]\left[1-\frac{2}{\pi} f_{A} R(L+1)^{3}\right]\right\}^{1 / 2}} \\
\text { Contribution to stress intensity factor from crack interaction } \\
\qquad K_{I C}=K_{I, 1}+K_{I, 2} \\
L=1 / \mathrm{a} \\
\begin{array}{l}a=\text { radius of micro-pore } \\
R=\sigma_{3} / \sigma_{1}\end{array} \\
\qquad f_{A}=\pi \mathrm{a}^{2} \mathrm{~N}_{\mathrm{A}}\end{array}$ & $\begin{array}{l}\text { Development of a fracture } \\
\text { model for failure of brittle } \\
\text { solids considering the } \\
\text { interaction between cracks. } \\
\text { Cracks are assumed to be } \\
\text { initiation from micro-pores } \\
\text { within the solid. Total stress } \\
\text { intensity factor is a } \\
\text { combination of a single crack } \\
\text { growth and the effect of } \\
\text { neighboring cracks. }\end{array}$ \\
\hline [97] & $\begin{array}{l}\qquad \sigma_{1}=\frac{-K_{I, 1} \sqrt{3}}{\sqrt{\pi c}\left[(1-R)-\left(1+\mu^{2}\right)^{\frac{1}{2}}-(1+R) \mu\right]} \\
L=1 / c \\
R=\sigma_{3} / \sigma_{1} \\
\text { Additional contribution caused by crack interaction } \\
\qquad \sigma_{1}=\frac{-K_{I, 2}}{\frac{\sqrt{2}}{\pi} D_{o} \frac{1}{2}\left(L+\frac{1}{\sqrt{2}}\right)^{\frac{1}{2}} \sqrt{\pi c}\left[\left(1-\frac{8}{\pi} D_{o} R\left(L+\frac{1}{\sqrt{2}}\right)^{3}\right)\left(1-\frac{2}{\pi} D_{o} R\left(L+\frac{1}{\sqrt{2}}\right)^{3}\right)\right]^{\frac{1}{2}}} \\
\qquad K_{I C}=K_{I, 1}+K_{I, 2} \\
D_{o}=\text { initial damage } \\
D_{o}=\pi c^{2} \mathrm{~N}_{\mathrm{A}} \\
\mathrm{N}_{\mathrm{A}}=\text { Number of initial cracks per unit area }\end{array}$ & $\begin{array}{l}\text { Similar to Nemat-Nasser and } \\
\text { Horii [92] 2D model. The crack } \\
\text { initiation model is extended by } \\
\text { considering the additional } \\
\text { contribution to the stress } \\
\text { intensity due to bending of } \\
\text { columns caused by } \\
\text { crack interaction. }\end{array}$ \\
\hline
\end{tabular}


Table 3. Cont.

\begin{tabular}{|c|c|c|}
\hline Refs. & Governing Equation & Remarks \\
\hline [100] & 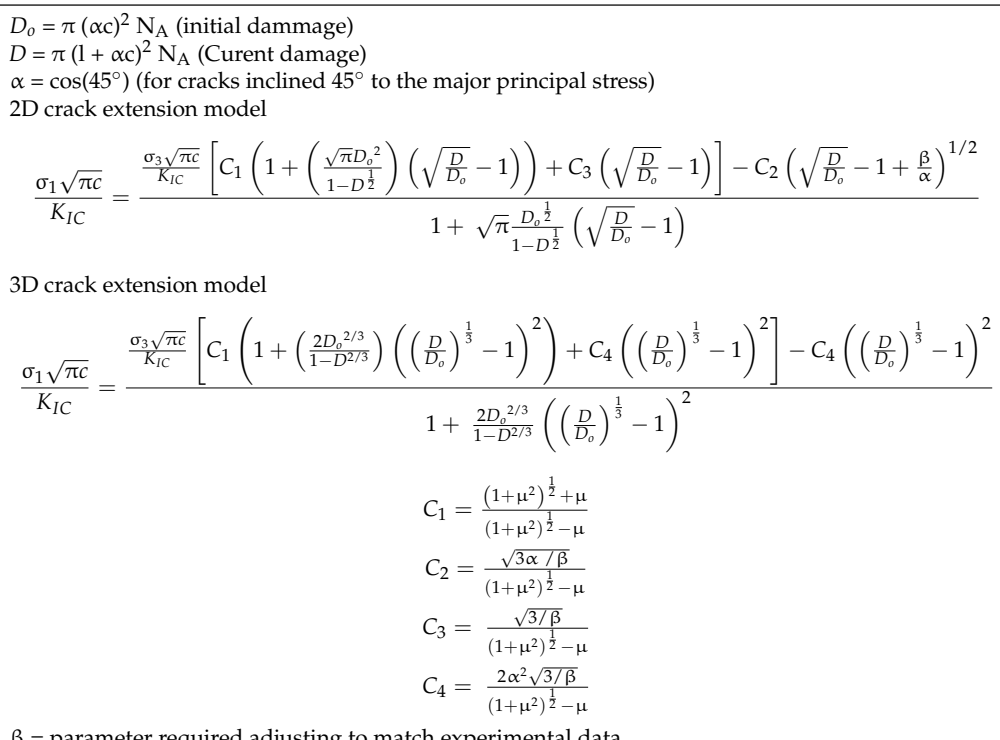 & $\begin{array}{l}\text { Incorporates damage } \\
\text { evolution into the model by } \\
\text { including the length of wing } \\
\text { crack } 1 \text { at constant confinement. } \\
\text { The 2D crack model was } \\
\text { extended to a 3D } \\
\text { penny-shaped crack } \\
\text { propagation model }\end{array}$ \\
\hline [96] & $\begin{array}{l}\qquad \sigma_{f}=\frac{K_{I C}}{(3 \alpha l)^{0.5}\left(\operatorname{Sin} \theta \operatorname{Cos} \theta-\mu \operatorname{Sin}^{2} \theta\right)} \\
\begin{array}{l}\theta=\text { angle between the initial flaw and the direction of major principal stress } \\
\alpha=1 / \mathrm{w} \text { (Figure 13) }\end{array}\end{array}$ & $\begin{array}{l}\text { Applicable when only under } \\
\text { uniaxial compression. Failure } \\
\text { initiated from bending of } \\
\text { microcolumns generated by } \\
\text { splay cracking. }\end{array}$ \\
\hline [95] & $\begin{array}{c}\sigma_{f}=\frac{2 K_{I C}}{\sqrt{c}\left[\left(1+\left(1-\mu \frac{1+R}{1-R}\right)^{\frac{2}{3}}\right)^{\frac{1}{2}}-1\right]^{\frac{1}{2}}\left(1+3 \mu^{2} \alpha^{2}\left(1-R^{2}\right)\right)^{\frac{1}{2}}} \\
\frac{l}{c}=\frac{1-R-\mu(1+R)}{4.3 R} \\
\alpha=\mathrm{h} / \mathrm{w} \text { (Figure 13) }\end{array}$ & $\begin{array}{l}\text { Developed from the Schulson } \\
\text { et al. [96] model. Incorporates } \\
\text { the frictional effect of adjacent } \\
\text { microcolumns to model failure. } \\
\text { Applicable under confined } \\
\text { conditions when: } \\
\qquad R=\frac{\sigma 3}{\sigma 1} \\
\qquad R<(1-\mu) /(1+\mu) \\
\text { and higher R-values prevent } \\
\text { frictional sliding. }\end{array}$ \\
\hline [101] & 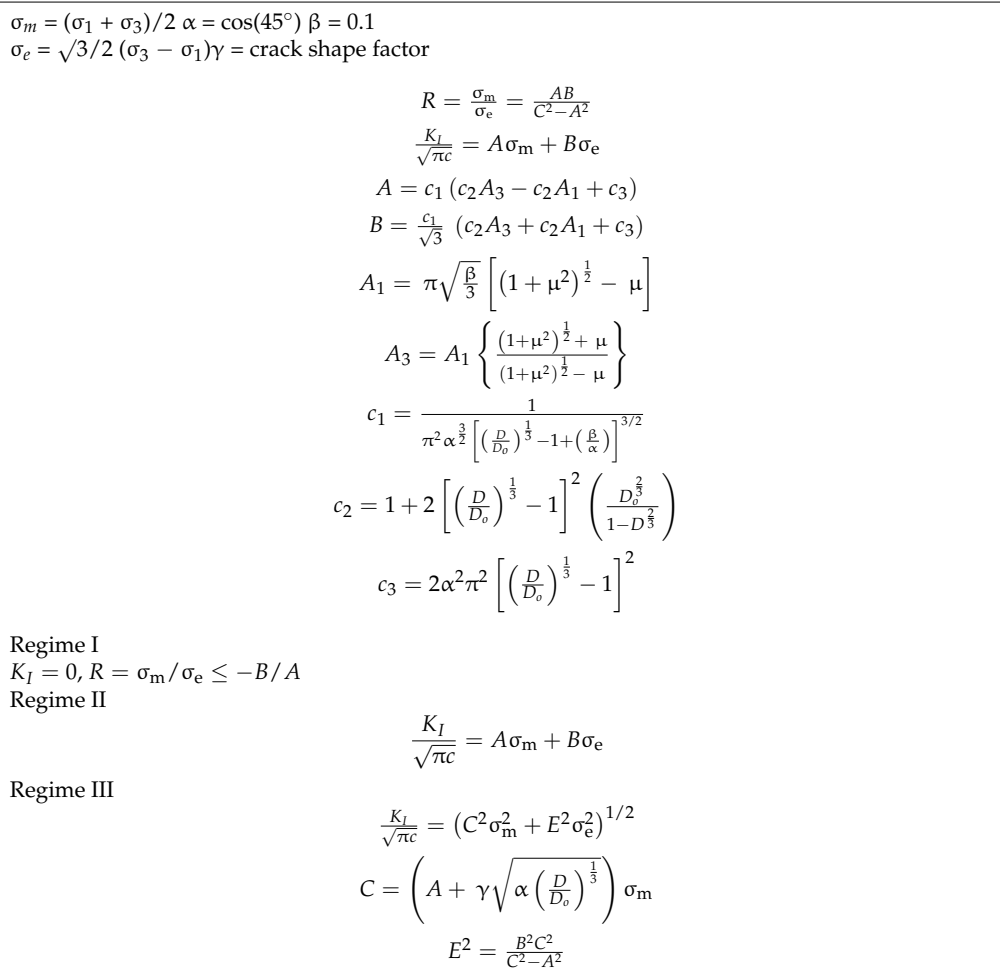 & $\begin{array}{l}\text { A generalized model for } \\
\text { arbitrary stress states } \\
\text { developed from Ashby and } \\
\text { Sammis [100] model. Defines } \\
\text { three regimes for applied } \\
\text { confinement ratios depending } \\
\text { on the crack surface } \\
\text { interactions. }\end{array}$ \\
\hline
\end{tabular}


A different mechanism for fracturing of rock due to pre-existing micro cracks has been proposed by Schulson et al. [96]. In addition to the initiation of wing cracks at the tip of existing micro fractures, the influence of additional cracks emanating adjacent to the wing crack (splay cracks) has been considered in the model. Here, failure of the rock mass is assumed to be initiated from the bending of the outermost microcolumn formed by wing crack and splay cracks. The bending is caused by the frictional sliding of the free end of the column ultimately leading to its failure. The microcolumn was assumed to be fixed at one end and free at the initial crack tip as shown in Figure 13c. The failure mechanisms suggested by Ashby and Hallam [97] and Schulson et al. [96] is shown in Figure 13d,e. Material failure results in between two wing cracks in the first, whereas material failure occurs within splay cracks in the latter. However, the results of the Schulson et al. [96] model yielded about two times smaller failure stress than actual measured stress, mainly due to the consideration of a single microcolumn for the crack propagation and neglecting the frictional resistance gained by the adjacent columns, which in whole underestimated the failure stress of the material.

This frictional influence of adjacent microcolumns on the failure of rock was therefore considered by Renshaw and Schulson [95] and found a twofold lesser failure stress compared to Horii and Nemat-Nasser [93] Ashby and Hallam [97] models. However, crack growth in all of these studies has been arrested at similar crack lengths when compressive forces normal to the crack growth direction present. As shown in Figure 14, under positive confinement ratios $(R>0)$ an exponential growth in normalized vertical stress can be seen beyond a particular crack length. Therefore, if an adequate hoop stress is developed around the injection well of a rock by the expansive pressure of SCDA, tensile stresses $(R<0)$ act perpendicular to the direction of crack growth further facilitating crack growth.

Ashby and Hallam [97] incorporated the effect of initial damage $D_{o}$ of the sample to the stress intensity equation (see Table 3 ) to properly describe the effect of crack interaction. However, this model failed to capture the effects due to the growth of damage in a rock mass and therefore was improved by Ashby and Sammis [100] by defining current damage D, which incorporates the effect of the extended wing cracks in the fracture model (Table 3). This 2D crack model was effectively extended to a 3D crack growth model by Ashby and Sammis [100] with the assumption that cracks initiated from the periphery of penny-shaped inclined cracks and the initial population of cracks have the same size.

Limiting factor of these developed models is that they are applicable only under proportional loading, where a constant confinement ratio is maintained under principal stress states as shown in (Figure 13a-c). For the purpose of describing the fracture mechanism of SCDA, the sliding crack models can be applicable with the assumption that tangential tensile stresses around the injection well proportionally increases with the radial compressive stress.

In 2008, Deshpande and Evans [101] generalized the damage model developed by Ashby and Sammis [100] for arbitrary stress states by incorporating stress intensity factor $\mathrm{K}_{\mathrm{I}}$ in terms of the first two stress invariants of the stress tensor (Table 3). Since, brittle materials exhibit plastic failure under high confinements and high strain rates $\left(\sim 1000 \mathrm{~s}^{-1}\right)$, this plasticity behaviour was also incorporated by Deshpande and Evans [101] model. Additionally, the model can also be used to describe the failure mechanism of brittle materials at both quasi-static and dynamic loading conditions, which is, therefore, applicable for SCDA fracking, because of the slow volume expansion rates in SCDA, a quasi-static $\left(1 \times 10^{-3} \sim 1 \times 10^{-2} \mathrm{~s}^{-1}\right)$ condition can be expected in SCDA fracking.

In this model, Deshpande and Evans [101] divided the behaviour of materials with initial microcracks under three different regimes of compression ratios:

- Regime I: no relative sliding along the faces of the inclined crack implying sufficient confinement is provided to keep the flanks of the wing cracks shut and material behaviour is similar to that of an intact material

- Regime II: frictional sliding along the faces of the inclined crack causing wing crack extension

- Regime III: loss of contact between the faces of the inclined crack caused by the sufficiently tensile mean stress $\sigma_{\mathrm{m}}$ and the crack propagation is caused purely by mode I failure. 
All these three regimes can exist in a rock when fractured using SCDA depending on the orientation of the pre-existing micro cracks in the rock mass with radial compression and tangential tensile stress fields. As shown in Figure 15, crack growth can be observed in the radial direction. At lower confinement propagation of radial cracks could be due to a combination of both regime II and regime III (low confining stresses permit the development of tangential tensile stresses around the borehole) and at higher confinements, the rock fracture predominantly occurs through regime II (large confining stresses keep the microcrack faces in contact).

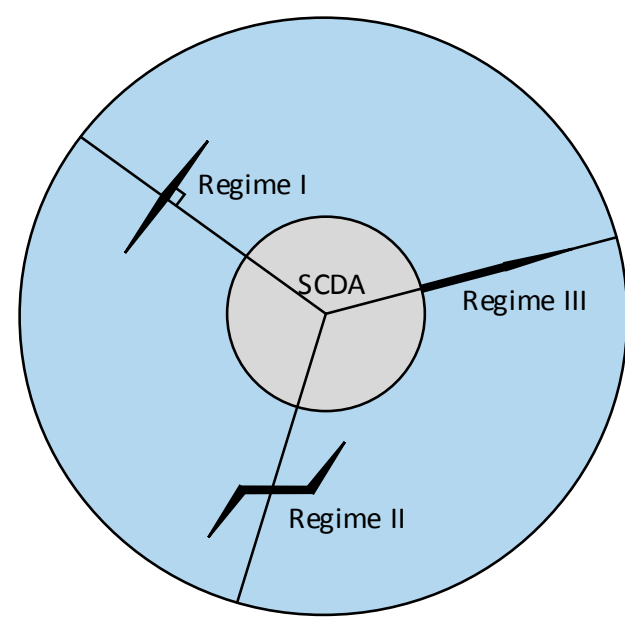

(a) Failure regimes based on crack orientation

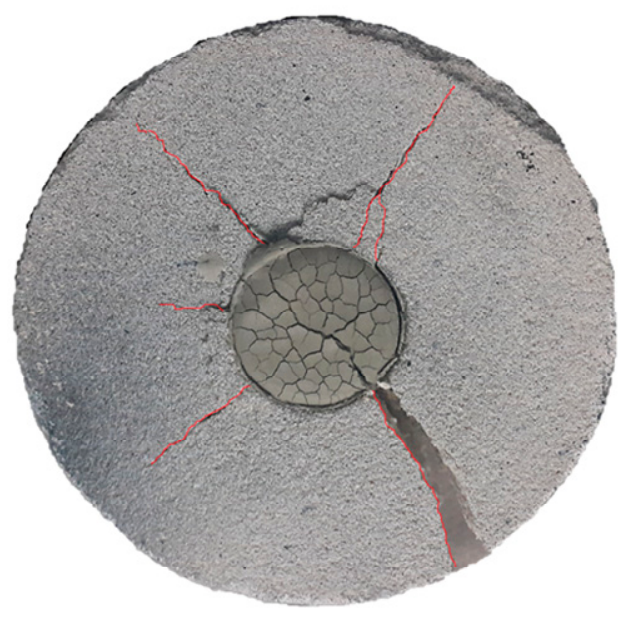

(b) Actual failure pattern

Figure 15. Failure regimes in rock fracturing using SCDA: (a) Possible failure regimes due to fracture orientation; (b) Observed fracture pattern from SCDA charging.

\section{Optimum Usage Strategies for Soundless Chemical Demolition Agent}

Optimum usage of SCDA is quite important in reducing the cost associated with the process and improving the fragmentation process. In this regard, borehole characteristics as diameter and spacing play a major role as expansive pressure development is occurred in there. However, to date, only a limited research has been conducted to find the optimum borehole spacing for a maximum usage of SCDA fracturing process [34,60,102-104]. Gomez and Mura [60] proposed a model to find the optimum borehole spacing $(S)$ as follows:

$$
S=k D
$$

in which, $D$ is the borehole diameter and $k$ is an experimental coefficient based on physical properties of different rock types and expansive cement given by Equation (13):

$$
k=\frac{\pi}{\sqrt{8}}\left\{\frac{4 \mu^{*}\left(1+v^{*}\right) \omega}{\left[\mu\left(1-2 v^{*}\right)+\mu^{*}\right] \sigma_{c}}\right\}^{1 / 2}
$$

where, $\sigma_{c}$ is the fracture stress of the rock; $\omega$ is the free expansion strain of the SCDA; $\mu, v$ are the shear modulus and Poisson's ratio of the rock material; and $\mu^{*}, \nu^{*}$ are corresponding quantities of SCDA filled hole. The experimental value of $k$ is found to be less than 10 for hard rocks, $8<k<12$ for medium hard rocks and $12<k<18$, for soft rocks.

A model proposed by Jin et al. [104] expressing the bore hole spacing $(S)$ as a function of the expansive pressure of SCDA $(p)$ tensile and compressive strengths of rock $\left(\sigma_{t}\right.$ and $\left.\sigma_{c}\right)$ as follows:

$$
S=2 D p\left(\frac{\sigma_{c}-\sigma_{t}}{\sigma_{c} \sigma_{t}}\right)
$$


A modified version of the Equation (14) was proposed by Wang et al. [103] to extend the model for more generous way as follows:

$$
S=2 D p\left(\frac{\sigma_{c}-\sigma_{t}}{\sigma_{c} \sigma_{t}}\right) \beta
$$

where, $\beta$ is an empirical coefficient which has the values $1,0.5,0.3$ for rock, concrete and reinforced concrete, respectively.

Arshadnejad [34] proposed Equation (16), more accurate expression, to find the optimum borehole spacing $(S)$ for rock fragmentation taking into account the tensile strength $\left(\sigma_{t}\right)$, time $(t)$ taken to reach an expansive pressure $(p)$ in the borehole at which failure takes place, elastic modulus of the rock $(E)$, diameter of the borehole $(D)$ and the mode I rock fracture toughness $\left(K_{I C}\right)$ :

$$
S=\left[-0.285\left(\frac{P}{\sigma_{t}}\right)^{2}+3.5\left(\frac{P}{\sigma_{t}}\right)-7.2\right] \frac{t^{2.7} E^{0.82} D^{2}}{K_{I C}^{2}}
$$

Though this model considers more variables in determining the borehole spacing compared to the other models, it still fails to capture the influence of one important fact, confining stresses acting on the rock mass, to date none has modeled to the best of our knowledge.

In Addition to the borehole spacing, the bore hole pattern also significantly affects the fragmentation characteristics using SCDA and therefore Laefer [39] using $38 \mathrm{~mm}$ diameter boreholes in large 32 concrete blocks with varying compressive strengths studied the crack propagation in concrete. The observed crack shape variations are shown in Figure 16. According to which, the majority (65\%) of the samples exhibit y shaped cracks with an angle around $120^{\circ}$ between each crack and the samples tested at an elevated ambient temperature $\left(39^{\circ} \mathrm{C}\right)$ showed greater crack density with multiple cracks generating from the borehole (Star pattern). This can be attributed to the greater degree of hydration occurring at higher temperatures resulting in a greater expansive pressure generation, which in turn produces a higher number of cracks. After the formation of the initial crack, other two cracks in the specimen was found to be formed due to the bending moments resulting in the fractured specimen. This bending moment is found to be maximum at $120^{\circ}$ angle direction from the initial crack and is caused by the expansive pressure of the borehole and the friction between the borehole surface and the hardened agent [5]. Considering this direction of fracture propagation, Harada et al. [5] recommended a hexagonal borehole pattern to optimize the fracture density of rock.

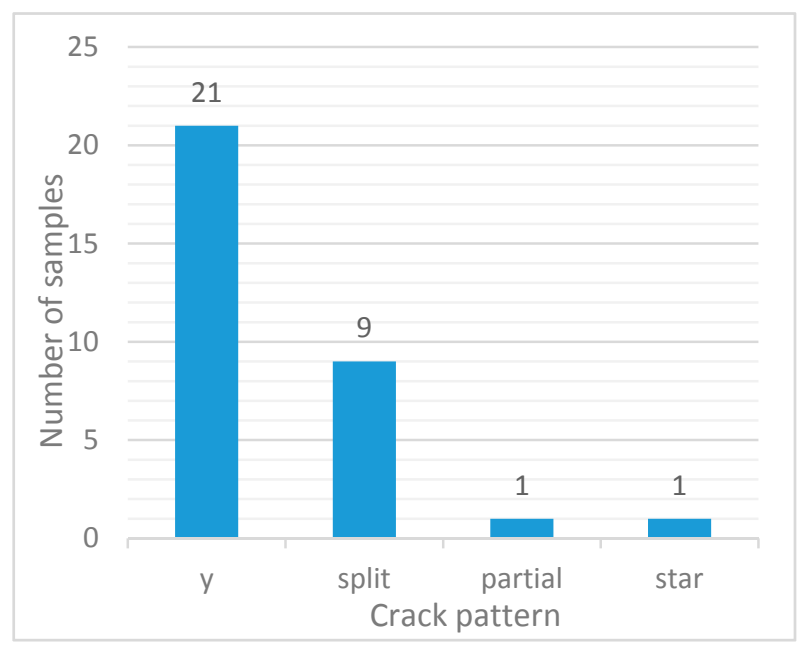

Figure 16. Observed crack patterns for SCDA assisted cracking [39].

Gambatese [36] used a different approach for an optimum SCDA fracking through reducing the usage of SCDA by introducing non-injected boreholes in the formation. According to their experimental 
research, crack migration towards non-injected boreholes is around $35 \%$ in a grid of $6 \times 6$ boreholes and reduced to less than $10 \%$ as the number of boreholes reduced to a grid of $3 \times 3$ in the same formation area. This shows the possibility of reducing SCDA usage through incorporating no injected boreholes. This is however required to be counter checked with the additional cost of drilling.

Hinze and Nelson [38] researched the possibility of enhancing SCDA performance by combining it with different additives, where expansive pressure reduction was observed after combining SCDA with different proportions of sand. It was found that replacing up to 50\% of SCDA with sand does not create any significant drop in the expansive pressure generation (a reduction of $14 \%$ from $28.7 \mathrm{MPa}$ to $24.6 \mathrm{MPa}$ at $24 \mathrm{~h}$ ). Further, a reduced the water content of SCDA to $27.5 \%$ from $30 \%$ was found to yield a $20 \%$ increment in expansive pressure generation after $24 \mathrm{~h}$ of mixing.

\section{Potential Applications of Soundless Chemical Demolition Agent}

Current usage of SCDA has been limited for rock quarrying due to the lack of understanding of the SCDA behavior in the fracturing process. It has mainly been used for demolition purposes in environments that are sensitive to excessive noise and vibration [105]. Substantial expansive pressures generating by SCDA, however, means it can be utilized in a number of many other applications.

The potential application of SCDA in hard igneous rock specimens subjected to uniaxial compression was investigated by Musunuri and Mitri [106] and obtained promising results which indicate SCDA can be effectively used for the fragmentation of uniaxially loaded rock specimens. A further development in the possible application of SCDA in shale fracturing for gas recovery has been studied by Guo et al. [107]. The experiment was conducted by drilling horizontal boreholes in horizontally and vertically confined shale samples and charging them with SCDA and found that volumetric fracturing with a complex fracture network could be made when multiple boreholes are used to fracture with SCDA. The expansive pressure of SCDA continues to develop even 4 days after mixing as long as a confinement is provided in the borehole [40]. Further hydration of $\mathrm{CaO}$ in SCDA results in a loss of confinement, at which point SCDA will gradually expand becoming highly porous material with reduced cohesion and eventually disintegrating into a fine powder (Figure 17). This behavior of SCDA can be used for a continuous fracturing process in unconventional gas reservoirs and the disintegration of the SCDA means there will not be any fluid flow obstruction in the well upon fracture completion. In comparison to conventional methods of hydrofracturing, fracturing using SCDA will largely reduce the required large quantities of water, downhole tools, extra fracturing pump trucks and therefore greatly reduces the total operational cost [107]. Unlike in hydraulic fracturing, there will not be any fluid-solid interaction in the rock mass during SCDA fracturing. Thus, SCDA fracking will result in reduced fracture length. However, this can be overcome by drilling additional boreholes in the reservoirs, which also creates a greater crack density. On the other hand, localized high-density cracks formed by using SCDA ensures that unlike in hydro-fracking, undesired cracks in gas and oil reservoirs which can cause complex issues such as ground water contamination are inhibited.

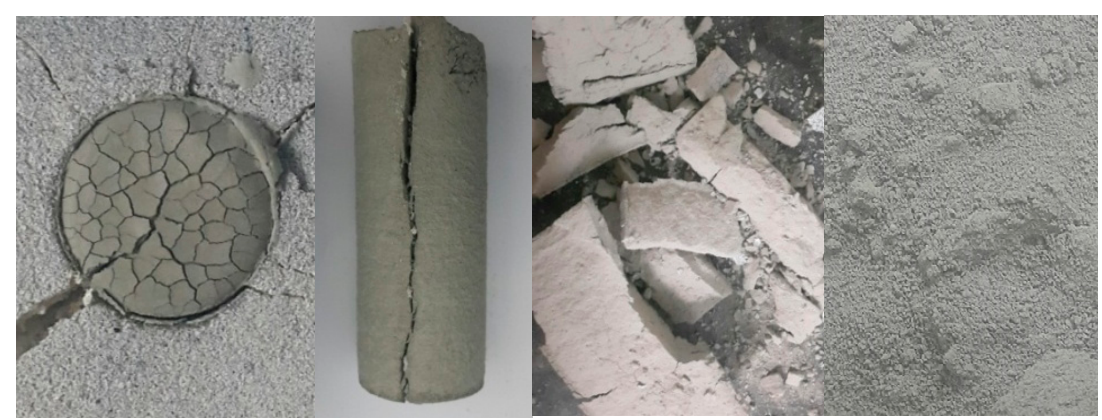

Figure 17. Disintegration of SCDA. 
The applicability of SCDA on the fracturing of rock has been studied by Guo et al. [69] by manipulating the gradual pressure development in SCDA to quantitatively characterize the growth of fracture network in an array of rock specimens ranging from Granite to siltstone. The surface fracture density in the experiment was found to be decreased with rock hardness, which varied from $17.2 \mathrm{~m}^{-1}$ for sandstone to $9.3 \mathrm{~m}^{-1}$ for granite. Depending on the orientation of rock discontinuities, complex fracture patterns were observed. Propagation of such complex fracture networks in the presence of bedding planes and other natural fractures means SCDA has the potential to improve the permeability of unconventional gas and oil reservoirs and orebodies during in-situ leaching (ISL) process.

Currently, shale gas recovery is limited by the method of hydraulic fracturing which involves large water pumping facilities and is subjected to a large public opposition. Fracturing using SCDA has comparatively less environmental impacts due to the volume expansion mechanism and post fracture disintegration nature of SCDA. If properly developed SCDA can be an effective alternative for hydraulic fracturing. Furthermore, at present ISL of minerals are limited to orebodies in porous, sedimentary rock masses. Most minerals with commercial value are originated in hard rock deposits. For instance, all of the accessible lithium in Australia occur in dense igneous pegmatite deposits [108]. In conventional methods of mineral recovery, nearly $70 \%$ of the cost of mining is spent on mineral extraction through mechanical crushers [30] and therefore fracturing using SCDA coupled with ISL could largely cut down the operational costs associated with overburden removal, transportation and mineral liberation in conventional mining.

\section{Limitations and Possible Improvements for Soundless Chemical Demolition Agent}

There are, however, many limitations existing with using SCDA in subsurface applications of deep mining and hydraulic fracturing. Thus, it is worth to know the cost of applications depending on its application.

\subsection{Washout Possibility}

Although there are many opportunities to use SCDA in deep earth applications, a major concern which has not yet been addressed is its poor applicability in saturated and saline rock formations. When SCDA mixed with water it forms a viscous slurry and like most cement slurries SCDA, therefore, washout in underwater applications. At present, no plausible method is available for the application of SCDA in underwater. Viscosity enhancing admixtures (VEA) are one option that can be considered to reduce the effect of washout. VEA's mainly based on natural polymers as welan gum, xanthan gum gellan gum and semi-synthetic polymers such as hydroxypropyl methylcellulose, hydroxyethyl cellulose, and carboxymethyl cellulose [109-111]. Experimental studies conducted on Portland cement by combining $0.05 \%-0.2 \%$ of VEA by mass of cement has exhibited favorable results with enhanced resistance against washout. However, the behavior of SCDA with the combination of VEA's has not yet been considered yet. Further, based on the proposed applications of SCDA, Calcium compatible and high-temperature tolerant welan gum, an anionic, high molecular weight polysaccharide is a probable candidate to enhance anti-washout properties of SCDA. The performance of VEA (welan gum) under saline conditions of oil fields has been tested by $\mathrm{Xu}$ et al. [112] and found that rheological properties of welan gum are weakened by saline conditions. The effect of salinity on SCDA water dilution resistance is really worth to investigate to enhance the performance of SCDA in submerged conditions.

\subsection{Flowability and Injectability}

SCDA reduces its fluidity rapidly after mixing. This is due to the low water content $(30 \%)$ in SCDA to gain maximum expansive pressure. If SCDA is to be injected in boreholes to form fractures the slurry has to maintain workability for prolonged periods. The addition of high range water reducing admixtures (HRWR) to SCDA has been previously reported in the literature [38,39]. But in both cases, the objective of using HRWR admixture was to further reduce the water content of the SCDA mix which contributes to the increase of expansive pressure generation. The sodium salt of 
naphthalene formaldehyde sulfonic acid is used as a superplasticizer in SCDA [39]. The long-chained organic molecules wrap hydrated cement particles and disperse cement particles with electrostatic repulsion [113]. However, increasing amounts of the compound also contributes to reducing the size of ettringite crystals formed during hydration [114], which may negatively affect the expansive properties of SCDA. Naphthalene-based HRWRs also show compatibility to be mixed in conjunction with welan gum [109] and it is essential to determine optimum mix proportions of both VEA and HRWR to produce a slurry sufficiently viscous to resist the water dilution while maintaining its fluidity.

\subsection{Performance in Deep Underground Conditions}

Deep reservoirs mostly consist of high saline brine and elevated temperatures. The effect of salinity on SCDA has not yet been tested properly. Nevertheless, experimental studies have been conducted on cement in high temperature and saline conditions [115]. Similarities in the mineralogy of cement and SCDA allows predicting the performance of SCDA in such conditions by observing the reactions of cement. Zhou et al. [115] found deterioration of ordinary Portland cement hydration characteristics with increasing concentrations of $\mathrm{NaCl}$ [115-117] and a similar effect can be expected for SCDA. Contradictorily Teodoriu and Asamba [118] have reported $5 \% \mathrm{NaCl}$ concentration by weight of water enhanced the $\mathrm{Ca}(\mathrm{OH})_{2}$ hydration process. At this concentration, similar to $\mathrm{CaCl}_{2}$ (which is an accelerator) $\mathrm{NaCl}$ acts as a catalyst for the precipitation of insoluble Calcium salt, which maintains a low $\mathrm{Ca}^{2+}$ concentration in the solution. Thus, the dissolution of $\mathrm{CaO}$ is accelerated which results in $\mathrm{Ca}(\mathrm{OH})_{2}$ hydration. Consequently, such concentrations of $\mathrm{NaCl}$ could effectively increase the expansive pressure generation of SCDA.

Another important aspect which will determine the performance of SCDA in subsurface applications is the need to overcome large confining pressures around boreholes due to in-situ stresses. The performance of SCDA tested under uniaxial conditions by Musunuri and Mitri [106] has not been extended to address the behavior of SCDA under large in-situ stresses. However, when evaluating the behavior of SCDA under large confinements, the effect of temperature with increasing depth has to be incorporated as it may be a vital component in enhancing the expansive pressure generated by SCDA. On average the global geothermal energy gradient varies from $20^{\circ} \mathrm{C} / \mathrm{km}$ to $30{ }^{\circ} \mathrm{C} / \mathrm{km}[119]$. For deep mining applications, the volatility of SCDA has to be studied with respect to the rate of hydration. Where SCDA require few hours $(5-9 \mathrm{~h})$ to produce the desired expansive pressure for fragmentation of rock at ambient temperatures, it is possible that due to the elevated temperatures in deep underground formations (shale gas and oil reservoirs, 1-3 km deep) SCDA can react at a more rapid rate. The behavior of SCDA under such high temperatures is not reported in the literature and need to be researched.

\section{Conclusions}

This study reviews up to date research on soundless cracking demolition agents (SCDA) application on rock fracturing including its limitations and strengths, possible applications in the petroleum industry and the possibility of using existing rock fragmentation models for SCDA based fracking. According to the conducted extensive review.

- Though SCDA method is an effective alternative for conventional rock fragmentation methods such as hydraulic fracturing and explosive blasting (those having proven environmentally detrimental repercussions), there is a lack of research conducted on this aspect which is confirmed by the poor standards available on SCDA usage.

- During the fracturing process, inside confined quarters SCDA is subjected to huge volumetric expansion as a result of the associated chemical reaction ( $\mathrm{CaO}$ hydration) and generates a large expansive pressure. Though this expansive pressure can be effectively used for the rock fragmentation process, proper quantification of it is necessary for a controllable effective rock fragmentation process. To date, several methods have therefore been reported in the literature to 
quantify the expansive pressure generated by SCDA, out of which the most widely used method being the outer pipe method.

- Quantifying the expansive pressure is complex due to its dependency on many factors including, water content, temperature and the arrangement of boreholes and its diameter. Among them, water content has a dominant influence on expansive pressure generation in SCDA, where high water contents require a higher degree of hydration of $\mathrm{Ca}(\mathrm{OH})_{2}$ to generate a particular expansive pressure, which therefore has a negative influence on expansive pressure generation. This $\mathrm{Ca}(\mathrm{OH})_{2}$ hydration process, however, also depends on the ambient temperature and borehole diameter, which are basically related to the heat of hydration in SCDA. The correlation between water content, temperature, and well diameter, degree of hydration and expansive pressure development has been well explained using Shalom's volume expansion mechanism for SCDA.

- Having a precise understanding of the fracture propagation mechanisms when using SCDA is imperative due to the generation of complex fracture networks by SCDA fracking in rocks. To date, some micromechanics based sliding crack models have been developed based on the tangential and radial stresses acting on the surrounded rock mass (conditions similar to boreholes charged with SCDA) and show the compatibility of SCDA fracturing mechanisms with the quasi-static fracturing mechanism that occur in Mode I type tensile failure.

- However, available fracture models in the literature haven't been developed exclusively for SCDA fracturing and instead existing micromechanics based fracture models have been used to identify the crack initiation, propagation and arrest criterions occur during the SCDA fracking.

- The effect of borehole diameter, spacing and the arrangement on expansive pressure generation and corresponding fracture network generation play a significant role in SCDA fracturing process and effective handling of them would make way to create an optimum fracture network in a targeted rock formation and therefore has been largely considered in the literature with many proposed models.

- $\quad$ SCDAs can be effectively utilized in many petroleum engineering (unconventional oil and gas recovery) and mineral processing (in-situ leaching of minerals) applications and such application can be promoted through manipulating the ability of SCDA to form controlled fracture networks. However, further extensive investigation of the performance of SCDA with respect to its potential applications are in need, particularly considering the issues in using SCDA such as washout effects in deep saturated rock high strata temperatures and high salinity in saline aquifers.

Acknowledgments: The authors would like to acknowledge the Department of Civil Engineering, Monash University for providing access to published material for successful completion of this review paper.

Author Contributions: The initial draft of the review paper was done by Radhika Vidanage De Silva. The drafted manuscript was reviewed and corrected by Mandadige Samintha Anne Perera. The concept was conceived by Ranjith Pathegama Gamage and also carried out the final check of the review paper.

Conflicts of Interest: The authors declare no conflict of interest. The founding sponsors had no role in the design of the study; in the collection, analyses, or interpretation of data; in the writing of the manuscript, and in the decision to publish the results.

\section{References}

1. World Bank. Energy Use (kg of Oil Equivalent Per Capita) Data. Available online: http://data.worldbank. org/indicator/EG.USE.PCAP.KG.OE (accessed on 15 June 2016).

2. Energy Information Administration. International Energy Outlook 2016; Energy Information Administration: Washington, DC, USA, 2016.

3. Fan, J.; Dou, L.; He, H.; Du, T.; Zhang, S.; Gui, B.; Sun, X. Directional hydraulic fracturing to control hard-roof rockburst in coal mines. Int. J. Min. Sci. Technol. 2012, 22, 177-181. [CrossRef]

4. Wang, F.; Tu, S.; Yuan, Y.; Feng, Y.; Chen, F.; Tu, H. Deep-hole pre-split blasting mechanism and its application for controlled roof caving in shallow depth seams. Int. J. Rock Mech. Min. Sci. 2013, 64, 112-121. [CrossRef] 
5. Harada, T.; Idemitsu, T.; Watanabe, A.; Takayama, S.-I. The design method for the demolition of concrete with expansive demolition agents. In Fracture Concrete and Rock; Springer: Berlin, Germany, 1989; pp. 47-57.

6. Jahed Armaghani, D.; Tonnizam Mohamad, E.; Hajihassani, M.; Alavi Nezhad Khalil Abad, S.V.; Marto, A.; Moghaddam, M.R. Evaluation and prediction of flyrock resulting from blasting operations using empirical and computational methods. Eng. Comput. 2016, 32, 109-121. [CrossRef]

7. Mohamad, E.T.; Armaghani, D.J.; Hasanipanah, M.; Murlidhar, B.R.; Alel, M.N.A. Estimation of air-overpressure produced by blasting operation through a neuro-genetic technique. Environ. Earth Sci. 2016, 75, 1-15.

8. Monjezi, M.; Hasanipanah, M.; Khandelwal, M. Evaluation and prediction of blast-induced ground vibration at shur river dam, iran, by artificial neural network. Neural Comput. Appl. 2013, 22, 1637-1643. [CrossRef]

9. Monjezi, M.; Rezaei, M.; Yazdian, A. Prediction of backbreak in open-pit blasting using fuzzy set theory. Expert Syst. Appl. 2010, 37, 2637-2643. [CrossRef]

10. Scoble, M.; Lizotte, Y.; Paventi, M.; Mohanty, B. Measurement of blast damage. Min. Eng. 1997, 49, $103-108$.

11. Zhi, S.; Elsworth, D. The role of gas desorption on gas outbursts in underground mining of coal. Geomech. Geophys. Geo-Energy Geo-Resour. 2016, 2, 151-171. [CrossRef]

12. Hasanipanah, M.; Armaghani, D.J.; Monjezi, M.; Shams, S. Risk assessment and prediction of rock fragmentation produced by blasting operation: A rock engineering system. Environ. Earth Sci. 2016, 75, 1-12. [CrossRef]

13. Morin, M.A.; Ficarazzo, F. Monte carlo simulation as a tool to predict blasting fragmentation based on the kuz-ram model. Comput. Geosci. 2006, 32, 352-359. [CrossRef]

14. Donaldson, E.C.; Alam, W.; Begum, N. Hydraulic Fracturing Explained: Evaluation, Implementation, and Challenges; Elsevier: Amsterdam, The Netherlands, 2014.

15. Smith, M.B.; Montgomery, C. Hydraulic Fracturing; CRC Press: Boca Raton, FL, USA, 2015.

16. Arthur, J.D.; Uretsky, M.; Wilson, P. Water Resources and Use for Hydraulic Fracturing in the Marcellus Shale Region; ALL Consulting: Tulsa, OK, USA, 2010.

17. Kondash, A.; Vengosh, A. Water footprint of hydraulic fracturing. Environ. Sci. Technol. Lett. 2015, 2, $276-280$. [CrossRef]

18. Winter, T.C. Ground Water and Surface Water: A Single Resource; DIANE Publishing: Darby, PA, USA, 1998.

19. Guglielmi, Y.; Cappa, F.; Avouac, J.-P.; Henry, P.; Elsworth, D. Seismicity triggered by fluid injection-induced aseismic slip. Science 2015, 348, 1224-1226. [CrossRef] [PubMed]

20. Ellsworth, W.L. Injection-induced earthquakes. Science 2013, 341, 1225942. [CrossRef] [PubMed]

21. Holland, A.A. Earthquakes triggered by hydraulic fracturing in south-central oklahoma. Bull. Seismol. Soc. Am. 2013, 103, 1784-1792. [CrossRef]

22. Osborn, S.G.; Vengosh, A.; Warner, N.R.; Jackson, R.B. Methane contamination of drinking water accompanying gas-well drilling and hydraulic fracturing. Proc. Natl. Acad. Sci. USA 2011, 108, 8172-8176. [CrossRef] [PubMed]

23. Cooley, H.; Donnelly, K.; Ross, N.; Luu, P. Hydraulic Fracturing and Water Resources: Separating the Frack from the Fiction; Pacific Institute: Oakland, CA, USA, 2012.

24. Environmental Protection Agency. Study of the Potential Impacts of Hydraulic Fracturing on Drinking Water Resources; Environmental Protection Agency: Washington, DC, USA, 2012.

25. Wanniarachchi, W.; Ranjith, P.; Perera, M.; Lashin, A.; Al Arifi, N.; Li, J. Current opinions on foam-based hydro-fracturing in deep geological reservoirs. Geomech. Geophys. Geo-Energy Geo-Resour. 2015, 1, 121-134. [CrossRef]

26. Waxman, H.A.; Markey, E.J.; DeGette, D. Chemicals Used in Hydraulic Fracturing; United States House of Representatives COEAC: Washington, DC, USA, 2011.

27. Palmer, C.; Sito, Z. Nitrogen and carbon dioxide fracturing fluids for the stimulation of unconventional shale plays. AGH Drill. Oil Gas 2013, 30, 191-198. [CrossRef]

28. McAndrew, J.; Fan, R.; Barba, R. Energized and Foam Fracturing Fluids for Liquids-Rich Organic Shale Reservoirs; Integrated Energy Services: Austin, TX, USA, 2014.

29. Andres, U. Electrical disintegration of rock. Miner. Proc. Extr. Metall. Rev. 1995, 14, 87-110. [CrossRef]

30. Andres, U. Development and prospects of mineral liberation by electrical pulses. Int. J. Miner. Proc. 2010, 97, 31-38. [CrossRef] 
31. Hirotoshi, I.; Igor, V.L.; Hidenori, A.; Izumi, N. Pulsed electric breakdown and destruction of granite. Jpn. J. Appl. Phys. 1999, 38, 6502.

32. Kuznetsov, Y.I.; Vazhov, V.F.; Zhurkov, M.Y. Electrical breakdown of solid dielectrics and rocks on the trailing edge of a voltage pulse. Russ. Phys. J. 2011, 54, 410-415. [CrossRef]

33. Lisitsyn, I.; Inoue, H.; Nishizawa, I.; Katsuki, S.; Akiyama, H. Breakdown and destruction of heterogeneous solid dielectrics by high voltage pulses. J. Appl. Phys. 1998, 84, 6262-6267. [CrossRef]

34. Arshadnejad, S.; Goshtasbi, K.; Aghazadeh, J. A model to determine hole spacing in the rock fracture process by non-explosive expansion material. Int. J. Miner. Metall. Mater. 2011, 18, 509-514. [CrossRef]

35. El Dessouki, A.; Mitri, H. Rock breakage using expansive cement. Engineering 2011, 3, 168. [CrossRef]

36. Gambatese, J.A. Controlled concrete demolition using expansive cracking agents. J. Constr. Eng. Manag. 2003, 129, 98-104. [CrossRef]

37. Harada, T.; Soeda, K.; Idemitsu, T.; Watanabe, A. Characteristics of Expansive Pressure of an Expansive Demolition Agent and the Development of New Pressure Transducers; Japan Society of Civil Engineers: Tokyo, Japan, 1994.

38. Hinze, J.; Nelson, A. Enhancing performance of soundless chemical demolition agents. J. Constr. Eng. Manag. 1996, 122, 193-195. [CrossRef]

39. Laefer, D.F.; Ceribasi, S.; Wortman, J.; Abrozevitch-Cooper, N.; Huynh, M.-P.; Midgette, J. Expansive fracture agent behaviour for concrete cracking. Mag. Concr. Res. 2010, 62, 443-452. [CrossRef]

40. Natanzi, A.S.; Laefer, D.F.; Connolly, L. Cold and moderate ambient temperatures effects on expansive pressure development in soundless chemical demolition agents. Constr. Build. Mater. 2016, 110, 117-127. [CrossRef]

41. Hinze, J.; Brown, J. Properties of soundless chemical demolition agents. J. Constr. Eng. Manag. 1994, 120, 816-827. [CrossRef]

42. Huynh, M.-P.; Laefer, D.F. Expansive cements and soundless chemical demolition agents: State of technology review. In Proceedings of the 11th Conference on Science and Technology, Ho Chi Minh City, Vietnam, 21-23 October 2009.

43. Betanomit Technical Manual-Non Explosive Cracking Agent. Available online: http://www.betonamit. com/technical-manual/ (accessed on 8 April 2016).

44. Bristar (for General Purpose/Bulk Type) Non-Explosive Demolition Agent Taiheiyo Materials Corporation. Available online: http://www.taiheiyo-m.co.jp/english/product/productSubtop_4/product_ 4/productEntry-e023.html (accessed on 8 April 2016).

45. Archer USA. Available online: http://www.dexpan.com/dexpan-non-explosive-controlled-demolitionagent-silent-cracking-breaking.aspx (accessed on 5 October 2016).

46. Expando, Expansive Mortar, Non Explosive Demolition Agent Used for Rock, Concrete Breaking. Available online: http:/ / www.expando.com.au/what-is-expando (accessed on 8 April 2016).

47. Ecobust. Available online: http://www.ecobust.com/ (accessed on 8 April 2016).

48. Nagataki, S.; Gomi, H. Expansive admixtures (mainly ettringite). Cem. Concr. Compos. 1998, 20, $163-170$. [CrossRef]

49. Konik, Z.; Małolepszy, J.; Roszczynialski, W.; Stok, A. Production of expansive additive to portland cement. J. Eur. Ceram. Soc. 2007, 27, 605-609. [CrossRef]

50. Standard Specification for Expansive Hydraulic Cement; ASTM International: West Conshohocken, PA, USA, 1996.

51. Soeda, K.; Harada, T. The mechanics of expansive pressure generation using expansive demolition agent. Doboku Gakkai Ronbunshu 1993, 1993, 89-96. [CrossRef]

52. Liu, X.; Li, Y. Effect of mgo on the composition and properties of alite-sulphoaluminate cement. Cem. Concr. Res. 2005, 35, 1685-1687. [CrossRef]

53. Horkoss, S.; Escadeillas, G.; Rizk, T.; Lteif, R. The effect of the source of cement SO 3 on the expansion of mortars. Case Stud. Constr. Mater. 2016, 4, 62-72. [CrossRef]

54. Kurdowski, W.; Thiel, A. On the role of free calcium oxide in expansive cements. Cem. Concr. Res. 1981, 11, 29-40. [CrossRef]

55. Bentur, A.; Ish-Shalom, M. Properties of type k expensive cement of pure components II: Proposed mechanism of ettringite formation and expansion in unrestrained paste of pure expansive component. Cem. Concr. Res. 1974, 4, 709-721. [CrossRef] 
56. Chatterji, S. Mechanism of expansion of concrete due to the presence of dead-burnt cao and mgo. Cem. Concr. Res. 1995, 25, 51-56. [CrossRef]

57. Ish-Shalom, M.; Bentur, A. Properties of type k expansive cement of pure components I: Hydration of unrestrained paste of expansive component-Results. Cem. Concr. Res. 1974, 4, 519-532. [CrossRef]

58. Nocuń-Wczelik, W.; Stok, A.; Konik, Z. Heat evolution in hydrating expansive cement systems. J. Therm. Anal. Calorim. 2010, 101, 527-532. [CrossRef]

59. Ghosh, S. Cement and Concrete Science and Technology; Thomas Telford: Telford, UK, 1991.

60. Gómez, C.; Mura, T. Stresses caused by expansive cement in borehole. J. Eng. Mech. 1984, 110, 1001-1005. [CrossRef]

61. Mehta, P.; Lesnikoff, G. Hydration characteristics and properties of shrinkage-compensating cements. In Proceedings of the 6th International Congress on the Chemistry of Cement, Moscow, Russia, 23-27 September 1974; pp. 89-115.

62. Polivka, M. Factors Influencing Expansion of Expansive Cement Concretes; Special Publications; Symantec Endpoint Protection Manager: Darlington, UK, 1973; Volume 38, pp. 239-250.

63. Boresi, A.P.; Chong, K.P. Elasticity in Engineering Mechanics; Elsevier Science Publishing Co., Inc.: New York, NY, USA, 1987.

64. Dowding, C.H.; Labuz, J.F. Closure to "fracturing of rock with expansive cement" by Charles H. Dowding and Joseph F. Labuz (October 1982). J. Geotech. Eng. 1983, 109, 1208-1209. [CrossRef]

65. Cohen, M. Modeling of expansive cements. Cem. Concr. Res. 1983, 13, 519-528. [CrossRef]

66. Ish-Shalom, M.; Bentur, A. Properties of type k expansive cement of pure components III: Hydration of pure expansive component under varying restraining conditions. Cem. Concr. Res. 1975, 5, 139-152. [CrossRef]

67. Kadri, E.; Aggoun, S.; De Schutter, G.; Ezziane, K. Combined effect of chemical nature and fineness of mineral powders on portland cement hydration. Mater. Struct. 2010, 43, 665-673. [CrossRef]

68. Dehghan, A.N.; Goshtasbi, K.; Ahangari, K.; Jin, Y. Experimental investigation of hydraulic fracture propagation in fractured blocks. Bull. Eng. Geol. Environ. 2015, 74, 887-895. [CrossRef]

69. Guo, T.; Zhang, S.; Ge, H.; Wang, X.; Lei, X.; Xiao, B. A new method for evaluation of fracture network formation capacity of rock. Fuel 2015, 140, 778-787. [CrossRef]

70. Mogi, K. Pressure Dependence of Rock Strength and Transition from Brittle Fracture to Ductile Flow; Earthquake Research Institute, University of Tokyo: Tokyo, Japan, 1966.

71. Klein, E.; Baud, P.; Reuschlé, T.; Wong, T. Mechanical behaviour and failure mode of bentheim sandstone under triaxial compression. Phys. Chem. Earth A Solid Earth Geod. 2001, 26, 21-25. [CrossRef]

72. Paquet, J.; François, P. Experimental deformation of partially melted granitic rocks at 600-900 c and $250 \mathrm{mpa}$ confining pressure. Tectonophys 1980, 68, 131-146. [CrossRef]

73. Bieniawski, Z.T. Mechanism of brittle fracture of rock. Int. J. Rock Mech. Min. Sci. Geomech. Abstr. 1967, 4, 395-406. [CrossRef]

74. Brace, W.F.; Paulding, B.W.; Scholz, C. Dilatancy in the fracture of crystalline rocks. J. Geophys. Res. 1966, 71, 3939-3953. [CrossRef]

75. Hallbauer, D.; Wagner, H.; Cook, N. Some observations concerning the microscopic and mechanical behaviour of quartzite specimens in stiff, triaxial compression tests. Int. J. Rock Mech. Min. Sci. Geomech. Abstr. 1973, 10, 713-726. [CrossRef]

76. Hoek, E.; Bieniawski, Z. Brittle fracture propagation in rock under compression. Int. J. Fract. Mech. 1965, 1, 137-155. [CrossRef]

77. Martin, C.; Chandler, N. The progressive fracture of lac du bonnet granite. Int. J. Rock Mech. Min. Sci. Geomech. Abstr. 1994, 31, 643-659. [CrossRef]

78. Scholz, C. Experimental study of the fracturing process in brittle rock. J. Geophys. Res. 1968, 73, 1447-1454. [CrossRef]

79. Tapponnier, P.; Brace, W. Development of stress-induced microcracks in westerly granite. Int. J. Rock Mech. Min. Sci. Geomech. Abstr. 1976, 13, 103-112. [CrossRef]

80. Wawersik, W.; Brace, W. Post-failure behavior of a granite and diabase. Rock Mech. 1971, 3, 61-85. [CrossRef]

81. Brace, W.F. Brittle fracture of rocks. In State of Stress in the Earth's Crust; Elsevier: New York, NY, USA, 1964; pp. 111-180.

82. Chang, S.-H.; Lee, C.-I.; Jeon, S. Measurement of rock fracture toughness under modes I and II and mixed-mode conditions by using disc-type specimens. Eng. Geol. 2002, 66, 79-97. [CrossRef] 
83. Irwin, G.R. Analysis of stresses and strains near the end of a crack traversing a plate. J. Appl. Mech. 1957, 24, 361-364.

84. Atkinson, B.K. Introduction to fracture mechanics and its geophysical applications. Fract. Mech. Rock 1987, 1-26. [CrossRef]

85. Clifton, R.J.; Simonson, E.R.; Jones, A.H.; Green, S.J. Determination of the critical-stress-intensity factor kic from internally pressurized thick-walled vessels. Exp. Mech. 1976, 16, 233-238. [CrossRef]

86. Atkinson, B.K. Subcritical crack growth in geological materials. J. Geophys. Res. Solid Earth 1984, 89, 4077-4114. [CrossRef]

87. Lockner, D.A.; Madden, T.R. A multiple-crack model of brittle fracture: 2. Time-dependent simulations. J. Geophys. Res.Solid Earth 1991, 96, 19643-19654. [CrossRef]

88. Bieniawski, Z.T. Fracture dynamics of rock. Int. J. Fract. Mech. 1968, 4, 415-430. [CrossRef]

89. Brace, W.F.; Bombolakis, E.G. A note on brittle crack growth in compression. J. Geophys. Res. 1963, 68, 3709-3713. [CrossRef]

90. Kachanov, M.L. A microcrack model of rock inelasticity part II: Propagation of microcracks. Mech. Mater. 1982, 1, 29-41. [CrossRef]

91. Kachanov, M.L. A microcrack model of rock inelasticity part I: Frictional sliding on microcracks. Mech. Mater. 1982, 1, 19-27. [CrossRef]

92. Nemat-Nasser, S.; Horii, H. Compression-induced nonplanar crack extension with application to splitting, exfoliation, and rockburst. J. Geophys. Res. Solid Earth 1982, 87, 6805-6821. [CrossRef]

93. Horii, H.; Nemat-Nasser, S. Compression-induced microcrack growth in brittle solids: Axial splitting and shear failure. J. Geophys. Res 1985, 90, 3. [CrossRef]

94. Nemat-Nasser, S.; Deng, H. Strain-rate effect on brittle failure in compression. Acta Metall. Mater. 1994, 42, 1013-1024. [CrossRef]

95. Renshaw, C.E.; Schulson, E.M. Universal behaviour in compressive failure of brittle materials. Nature 2001, 412, 897-900. [CrossRef] [PubMed]

96. Schulson, E.M.; Iliescu, D.; Renshaw, C.E. On the initiation of shear faults during brittle compressive failure: A new mechanism. J. Geophys. Res. Solid Earth 1999, 104, 695-705. [CrossRef]

97. Ashby, M.F.; Hallam, S.D. The failure of brittle solids containing small cracks under compressive stress states. Acta Metall. 1986, 34, 497-510. [CrossRef]

98. Rose, L. Effective fracture toughness of microcracked materials. J. Am. Ceram. Soc. 1986, 69, $212-214$. [CrossRef]

99. Sammis, C.; Ashby, M. The failure of brittle porous solids under compressive stress states. Acta Metall. 1986, 34, 511-526. [CrossRef]

100. Ashby, M.; Sammis, C. The damage mechanics of brittle solids in compression. Pure Appl. Geophys. 1990, 133, 489-521. [CrossRef]

101. Deshpande, V.; Evans, A. Inelastic deformation and energy dissipation in ceramics: A mechanism-based constitutive model. J. Mech. Phys. Solids 2008, 56, 3077-3100. [CrossRef]

102. Zhongzhe, J.; Hong, L.; Wen, Z.; Kasai, Y. Splitting mechanism of rock and concrete under expansive pressure. In Proceedings of the Conference of Demolition and Reuse of Concrete and Masonry, Demolition Method and Practice, Tokyo, Japan, 7-11 November 1988; pp. 141-148.

103. Wang, Y.S.; You, B.K.; Zhang, G.Q. Application of soundless cracking agent in china. In Demolition and Reuse of Concrete and Masonry; Chemical Rubber Company Press: Abingdon, UK, 1988; p. 149.

104. Jin, Z.Z.; Liao, H.; Zhu, W. Splitting mechanism of rock and concrete under expansive pressure. In Demolition and Reuse of Concrete and Masonry; Chemical Rubber Company Press: Abingdon, UK, 1988; p. 141.

105. Natanzi, A.S.; Laefer, D.F. Using chemicals as demolition agents near historic structures. In Proceedings of the 9th International Conference on Structural Analysis of Historical Constructions, Mexico City, Mexico, 14-17 October 2014.

106. Musunuri, A.; Mitri, H. Laboratory investigation into rock fracturing with expansive cement. Int. J. Min. Miner. Eng. 2009, 1, 327-345. [CrossRef]

107. Guo, T.; Zhang, S.; Ge, H.; Qu, Z. A novel "soundless cracking agent fracturing" for shale gas reservoir stimulation. Int. J. Environ. Sci. Dev. 2015, 6, 681. [CrossRef]

108. Australia's Identified Mineral Resources 2013; No. 78988; Geoscience Australia: Canberra, Australia, 2014. 
109. Khayat, K.H. Viscosity-enhancing admixtures for cement-based materials-An overview. Cem. Concr. Compos. 1998, 20, 171-188. [CrossRef]

110. Lachemi, M.; Hossain, K.; Lambros, V.; Nkinamubanzi, P.-C.; Bouzoubaâ, N. Self-consolidating concrete incorporating new viscosity modifying admixtures. Cem. Concr. Res. 2004, 34, 917-926. [CrossRef]

111. Patural, L.; Marchal, P.; Govin, A.; Grosseau, P.; Ruot, B.; Deves, O. Cellulose ethers influence on water retention and consistency in cement-based mortars. Cem. Concr. Res. 2011, 41, 46-55. [CrossRef]

112. Xu, L.; Xu, G.; Liu, T.; Chen, Y.; Gong, H. The comparison of rheological properties of aqueous welan gum and xanthan gum solutions. Carbohydr. Polym. 2013, 92, 516-522. [CrossRef] [PubMed]

113. Plank, J.; Hirsch, C. Impact of zeta potential of early cement hydration phases on superplasticizer adsorption. Cem. Concr. Res. 2007, 37, 537-542. [CrossRef]

114. Hekal, E.E.; Kishar, E.A. Effect of sodium salt of naphthalene-formaldehyde polycondensate on ettringite formation. Cem. Concr. Res. 1999, 29, 1535-1540. [CrossRef]

115. Zhou, X.; Lin, X.; Huo, M.; Zhang, Y. The hydration of saline oil-well cement. Cem. Concr. Res. 1996, 26, 1753-1759. [CrossRef]

116. Nasvi, M.; Ranjith, P.; Sanjayan, J.; Haque, A.; Li, X. Mechanical behaviour of wellbore materials saturated in brine water with different salinity levels. Energy 2014, 66, 239-249. [CrossRef]

117. Rocha, C.A.A.; Simão, C.A.; Cordeiro, G.C.; Toledo Filho, R.D. Effect of the sodium and potassium chloride on the mechanical and plastic properties on the oil well cement slurries. In Proceedings of the 31st International Conference on Ocean, Offshore and Arctic Engineering, Rio de Janeiro, Brazil, 10-15 June 2012.

118. Teodoriu, C.; Asamba, P. Experimental study of salt content effect on class g cement properties with application to well integrity. J. Nat. Gas Sci. Eng. 2015, 24, 324-329. [CrossRef]

119. Suggate, R. Relations between depth of burial, vitrinite reflectance and geothermal gradient. J. Pet. Geol. 1998, 21, 5-32. [CrossRef]

(C) 2016 by the authors; licensee MDPI, Basel, Switzerland. This article is an open access article distributed under the terms and conditions of the Creative Commons Attribution (CC-BY) license (http://creativecommons.org/licenses/by/4.0/). 